\title{
Global variability of phytoplankton functional types from space: assessment via the particle size distribution
}

\author{
T. S. Kostadinov ${ }^{1,2}$, D. A. Siegel ${ }^{1,3}$, and S. Maritorena ${ }^{1}$ \\ ${ }^{1}$ Earth Research Institute, University of California, Santa Barbara, CA 93106-3060, USA \\ ${ }^{2}$ Interdepartmental Graduate Program in Marine Science, University of California, Santa Barbara, CA, USA \\ ${ }^{3}$ Department of Geography, University of California, Santa Barbara, CA, USA
}

Received: 4 May 2010 - Published in Biogeosciences Discuss.: 8 June 2010

Revised: 18 September 2010 - Accepted: 21 September 2010 - Published: 20 October 2010

\begin{abstract}
A new method of retrieving the parameters of a power-law particle size distribution (PSD) from ocean color remote sensing data was used to assess the global distribution and dynamics of phytoplankton functional types (PFT's). The method retrieves the power-law slope, $\xi$, and the abundance at a reference diameter, $N_{0}$, based upon the shape and magnitude of the particulate backscattering coefficient spectrum. Relating the PSD to PFT's on global scales assumes that the open ocean particulate assemblage is biogenic. The retrieved PSD's can be integrated to define three size-based PFT's by the percent volume concentration contribution of three phytoplankton size classes - picoplankton $(0.5-2 \mu \mathrm{m}$ in equivalent spherical diameter), nanoplankton $(2-20 \mu \mathrm{m})$ and microplankton $(20-50 \mu \mathrm{m})$. Validation with in-situ HPLC diagnostic pigments resulted in better matchups for the pico- and micro-phytoplankton size classes as compared to nanoplankton. Global decadal averages derived from SeaWiFS monthly data reveal PFT and particle abundance spatial patterns that are consistent with current understanding. Oligotrophic gyres are characterized by lower particle abundance and higher contribution by picoplanktonsized particles than transitional or eutrophic regions. Seasonal succession patterns for size-based PFT's reveal good correspondence between increasing chlorophyll concentration and percent contribution by microplankton, as well as increasing particle abundance. Long-term trends in particle abundances are generally well correlated with the MEI index indicating increased oligotrophy (i.e. lower particle abun-
\end{abstract}

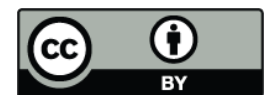

Correspondence to: T. S. Kostadinov (tiho@eri.ucsb.edu) dance and increased contribution of picoplankton-sized particles) during the warm phase of an El Niño event. This work demonstrates the utility and future potential of assessing phytoplankton functional types using remote characterization of the particle size distribution.

\section{Introduction}

The World Ocean profoundly influences Earth's habitability and plays a key role in the formation and regulation of climate via several key physical and biological processes and the ensuing feedbacks (IPCC, 2007). Oxygenic photosynthetic activity by phytoplankton was the single most important factor that led to the current oxygen replete atmosphere (e.g. Falkowski et al, 1998; 2003; Keeling et al., 2010), and phytoplankton are responsible for about half of the world's net photosynthetic production of $\sim 105 \mathrm{Gt} C$ per year (Field et al., 1998). The biological pump, powered by phytoplankton photosynthesis, is one of the ways that ocean biology influences atmospheric $\mathrm{CO}_{2}$ concentration, by altering the rain of organic particles to depth. Oceanic ecosystems are composed of microbes with different functions and biogeochemical roles. For example, small pico-phytoplankton species dominate the oligotrophic regions of the sea because of their efficiency in utilizing remineralized nutrients, whereas large phytoplankton groups such as diatoms are found in nutrient replete waters and their presence increases the efficiency of the biological pump (e.g. Eppley and Peterson, 1979; Cho and Azam, 1988; Falkowski et al., 1998, 2003). Ultimately, understanding the spatial and temporal distribution and variability of different phytoplankton species according to their

Published by Copernicus Publications on behalf of the European Geosciences Union. 
biogeochemical role is of paramount importance if we are to understand and predict the ocean's role in climate and climate change (e.g., Le Quéré et al., 2005; Hood et al., 2006).

The species diversity and complexity of the global ocean phytoplankton populations requires a reductionist approach to biogeochemical modeling. Thus, species with similar biogeochemical roles and physiological traits are grouped into the so-called phytoplankton functional types (PFT's). PFT's should share similar growth and mortality rates as well as response to temperature, nutrient and light conditions (e.g., Le Quéré et al., 2005). A major defining trait of the PFT's is their characteristic size (Le Quéré et al., 2005), which is also a major factor determining particle sinking rates and thus their role in $\mathrm{CO}_{2}$ sequestration (e.g. Eppley et al., 1967; McCave, 1975; Stemmann et al., 2004; Buesseler et al., 2007). Here, three PFT's are considered according to particle diameter - picoplankton $(<2 \mu \mathrm{m})$, nanoplankton $(2-20 \mu \mathrm{m})$, and microplankton $(>20 \mu \mathrm{m})$ (Sieburth et al., 1978). Vidussi et al. (2001) developed a method for the assessment of relative contribution of these groups to biomass, based on insitu HPLC analysis of diagnostic pigments. However, insitu observations are spatially and temporally sparse, and only satellite-borne remote sensing can provide the necessary spatio-temporal scales of observation required to provide a better understanding of the structure and function of global oceanic ecosystems and their role in climate and climate change (e.g., McClain, 2009).

Satellite ocean color observations have provided valuable synoptic views of oceanic ecosystems (e.g. O'Reilly et al., 1998; McClain et al., 2004; McClain, 2009). The normalized water-leaving radiance, $L_{\mathrm{wN}}(\lambda)$ (equivalently, the remote-sensing reflectance, $R_{\mathrm{rs}}(\lambda)$, e.g. Morel and Mueller, 2003) quantifies ocean color and is the principal satellite ocean color data product. Modern bio-optical algorithms use band ratios of $L_{\mathrm{wN}}(\lambda)$ (e.g. O'Reilly et al., 1998; Stramski et al., 2008) or semi-analytical relationships (e.g. Garver and Siegel, 1997; Loisel and Stramski 2000; Maritorena et al., 2002; Lee et al., 2002) to retrieve chlorophyll-a concentration (chl) and/or other biogeochemically relevant water constituents. To first order, chl is a great tool for productivity assessments (Behrenfeld and Falkowski, 1997), but independent knowledge of phytoplankton carbon (Behrenfeld et al., 2005) and PFT's (Le Quéré et al., 2005) is needed for validating modern biogeochemical models of pelagic ecosystem dynamics. This has prompted the recent development of various methods to retrieve PFT information from satellite ocean color data (see Nair et al. (2008) for a summary). In particular, Uitz et al. (2006) developed a method to assess PFT contributions using satellite chl data based on statistical relationships derived from a global in-situ HPLC data set. Further, Alvain et al. $(2005,2008)$ relied on second-order spectral effects on $L_{\mathrm{wN}}(\lambda)$ to classify normalized spectra into six dominant phytoplankton groups, also based on in-situ diagnostic pigment data.
Here, we apply a novel, alternative approach to assess sizebased PFT's using ocean color satellite data. Our approach is based upon the Kostadinov et al. (2009) method for retrieving the parameters of a power-law particle size distribution (PSD) using spectral retrievals of the particle backscattering coefficient. This algorithm is independent of in-situ diagnostic pigment determinations as well as satellite chl determinations. The retrieved PSD parameters are the PSD slope $(\xi)$ and the particle abundance at the reference diameter of $2 \mu \mathrm{m}$ $\left(N_{0}\right)$ for an assumed power-law PSD relationship. The PSD slope can be used to define the PFT's as the volume concentration contribution of the three classical size classes picoplankton, nanoplankton and microplankton (Sieburth et al., 1978). Thus, the PSD based method of PFT retrieval is size-based, rather than taxonomically based, and relies only on retrievals of the particulate backscattering spectrum. In addition, since the PFT's are expressed as percent contribution, they are independent of the absolute value of backscattering and thus of the value of $N_{0}$.

We first introduce this novel PSD-based method of retrieving global maps of PFT's from ocean color satellite observations. A validation is then performed against existing in-situ HPLC global data sets, using the diagnostic phytoplankton pigment method of Vidussi et al. (2001). Monthly SeaWiFS retrieval maps are then used to (1) compute global decadal averages and discuss them in the context of current knowledge of oceanic ecosystems, comparing the results to the existing methodologies of Uitz et al. (2006) and Alvain et al. (2008); (2) assess seasonal succession at several wellstudied sites in the Northern Hemisphere Atlantic and Pacific Oceans, and along meridional transects; (3) investigate regional and global scale decadal anomaly trends in the PFT's and compare these to established chlorophyll and/or productivity trends, as well as the state of the El Niño/Southern Oscillation.

\section{Data and methods}

\subsection{Satellite data and PSD algorithm}

Global monthly Level 3 mapped (1/12 degree resolution) SeaWiFS images of $L_{\mathrm{wN}}(\lambda)$ at $412,443,490,510$ and $555 \mathrm{~nm}$ and chlorophyll- $a$ concentration (chl; OC4v4 algorithm (O'Reilly et al., 2000)) from Sept. 1997 to Dec. 2007 were downloaded from NASA GSFC (http://oceancolor.gsfc. nasa.gov/; reprocessing 5.2). Images were down-sampled to $1 / 4$ degree resolution by taking the median in each 3-by3 pixel box if more than 5 pixels in the original data were valid. Subsequent analyses were performed on the $1 / 4$ degree resolution imagery unless otherwise noted. Daytime monthly SST data (Pathfinder v5.0), were also resampled from a $4 \mathrm{~km}$ resolution to match the PSD data fields.

Parameters of a power-law PSD were determined following the algorithm of Kostadinov et al. (2009). Briefly, the 
PSD algorithm retrieves the PSD slope, $\xi$, and the differential number concentration, $N_{0}$, of a power-law PSD, described by

$N(D)=N_{0}\left(\frac{D}{D_{0}}\right)^{-\xi}$

where $N(D)$ is the number of particles per volume of seawater normalized by the size bin width (units of $\mathrm{m}^{-4}$ ), $D$ is the particle diameter [m], and $D_{0}$ is a reference diameter (here, $2 \mu \mathrm{m})$ at which $N_{0}=N\left(D_{0}\right) . L_{\mathrm{wN}}(\lambda)$ was first used to retrieve the spectral particle backscattering coefficient, $b_{\mathrm{bp}}(\lambda)$, using the procedures described in Loisel et al. (2006). The $b_{\mathrm{bp}}(\lambda)$ imagery was used to calculate the spectral slope of backscattering at each pixel, $\eta$. The remote estimates for $\eta$ and $b_{\mathrm{bp}}$ (440) were used as inputs to the PSD algorithm, which uses theoretically derived look-up tables to solve for $\xi$ and $N_{0}$. Further details of the retrieval of PSD parameters and a full discussion of uncertainty propagation can be found in Kostadinov et al. (2009).

\subsection{Definition and retrieval of phytoplankton functional types}

Given $\xi$ and $N_{0}$, Eq. (1) can be integrated to estimate particle number and volume concentration in any given size range. We define the PFT's as the percent volume contribution made by a given size-defined and biogeochemically relevant PFT to the total particle volume in the 0.5 to $50 \mu \mathrm{m}$ diameter range. Thus, absolute number concentrations and the PFT's were calculated from $\xi$ and $N_{0}$ and monthly images for picoplankton-sized particles ( 0.5 to $2 \mu \mathrm{m}$ in diameter), nanoplankton-sized particles ( 2 to $20 \mu \mathrm{m})$ and microplankton-sized particles (20 to $50 \mu \mathrm{m}$ ) (Sieburth et al., 1978; Vidussi et al., 2001; Kostadinov et al., 2009) were produced. This PFT definition is different from categorical classifications, where a pixel is unambiguously assigned to a PFT (e.g. Alvain et al., 2008). The equations used to calculate the number concentrations and volume contributions are given by Eqs. (5) and (6) in Kostadinov et al. (2009). Solving these equations for percent contribution of a given size class to volume concentration (PBv_PFT) yields:

PBv_PFT $=\frac{D_{\mathrm{PFT}-\max }^{4-\xi}-D_{\mathrm{PFT}-\min }^{4-\xi}}{D_{\max }^{4-\xi}-D_{\min }^{4-\xi}}$

where $D_{\mathrm{PFT}-\min }$ and $D_{\mathrm{PFT}-\max }$ are the size limits of the PFT size class of interest and $D_{\min }=0.5 \mu \mathrm{m}$ and $D_{\max }=50 \mu \mathrm{m}$ are the size limits of the entire size range considered. If $\xi=4$ exactly, PFT's can be calculated as:

PBv_PFT $=\frac{\ln \left(\frac{D_{\text {PFT }- \text { max }}}{D_{\text {PFT }-\min }}\right)}{\ln \left(\frac{D_{\max }}{D_{\min }}\right)}$

The PFT's defined as in Eq. (2) are independent of the determination of $N_{0}$ and are thus functions of the PSD powerlaw slope, $\xi$. Figure 1 shows a plot of these functions for

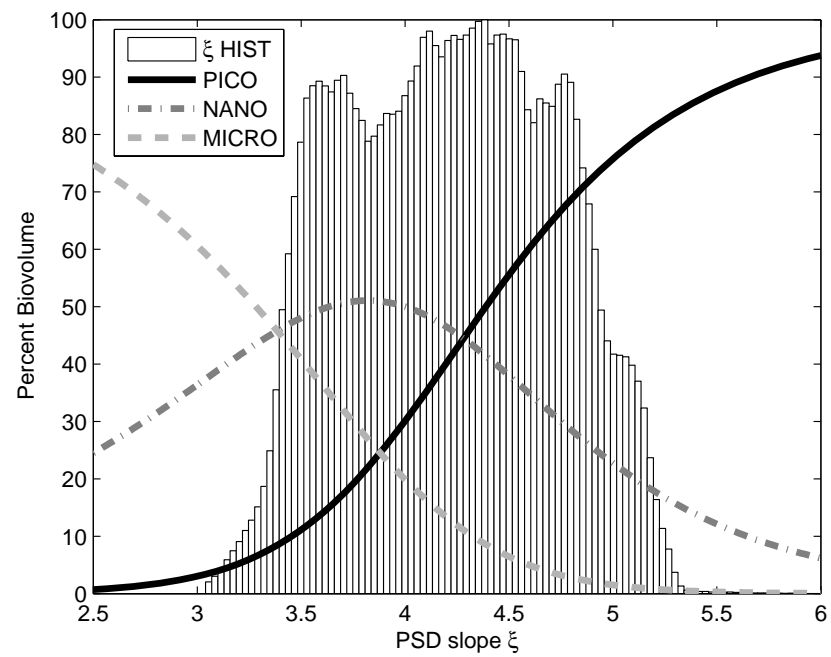

Fig. 1. The phytoplankton functional types (PFT's), plotted as a function of the power-law slope of the PSD (Eq. 2). PFT's are defined here as the percent volume contribution of three phytoplankton size classes to total particle volume concentration in the phytoplankton-size range (here, 0.5 to $50 \mu \mathrm{m}$ ). The three PFT classes are picoplankton ( 0.5 to $2 \mu \mathrm{m}$ in diameter), nanoplankton (2 to $20 \mu \mathrm{m})$, and microplankton $(20$ to $50 \mu \mathrm{m})$. The global histogram of the mean SeaWiFS-derived PSD slope $\xi$ (Fig. 4c) is superimposed to illustrate the range of geophysically occurring values of the PFT's according to the PSD algorithm. The histogram counts are normalized by the number of observations in the highest count bin.

the three PFT's defined here, superimposed on the histogram of actual $\xi$ values from the monthly global decadal average (see below). As expected, relative dominance of picoplankton monotonically increases with increasing $\xi$, and the importance of microplankton monotonically increases with decreasing $\xi$. However, values of $\mathrm{dPBv} \_\mathrm{PFT} / \mathrm{d} \xi$ are not constant. The percent contribution by nanoplankton-sized particles for much of the naturally occurring values of $\xi$ ranges from 35 to $50 \%$. As defined here, nanoplankton particles can never contribute more than $51 \%$ (Fig. 1).

\subsection{Phytoplankton pigment validation of the PSD-based PFT estimates}

A global in-situ HPLC phytoplankton pigment data set was assembled for construction of match-ups with SeaWiFS daily Level 3 data in order to validate the satellite PFT retrievals. The SEABASS data set (Werdell et al. (2003); http://seabass. gsfc.nasa.gov/seabasscgi/pigment_search.cgi) was merged with the BIOSOPE data set (Claustre et al., 2008) and part of the data set used in Uitz et al. (2006). All records with valid entries for the seven diagnostic pigments of Vidussi et al. (2001) (zeaxanthin, total chlorophyll-b, alloxanthin, 19' hexanoyloxyfucoxanthin, 19'-butanoyloxyfucoxanthin, fucoxanthin and peridinin) were selected for match-ups. The 
merged data set was further quality-controlled by replacing all entries below detection limits (vary by investigator and pigment, here $0.001 \mathrm{mg} \mathrm{m}^{-3}$ was used) by zeros. Only near-surface samples (taken from depths between $0 \mathrm{~m}$ and $25 \mathrm{~m}$ ) from waters with a bathymetric depth greater than $200 \mathrm{~m}$ were used (based on the 2001 ETOPO2 data set by the National Geophysical Data Center, NOAA, US Dept. of Commerce). In-situ percent biomass due to picoplankton, nanoplankton and microplankton was computed for each sample following the pigment ratio method of Vidussi et al. (2001). SeaWiFS match-ups from the same date as the sample were constructed using the single pixel from Level-3 $9 \mathrm{~km}$ binned daily data (Reprocessing 2009) that contained the HPLC sample (Maritorena et al., 2010). In cases when more than one in-situ observation corresponded to the same satellite pixel, the median of the in-situ PFT determinations was taken, only if the standard deviation of the duplicate samples did not exceed $20 \%$ of the mean for all three PFT determinations.

\subsection{Spatial and temporal statistics calculations}

Global decadal averages were calculated by taking the mean and standard deviation of all available monthly observations at each pixel. SST, chl, PSD slope $\xi$ and PFT statistics were calculated in linear space, whereas number concentration statistics were calculated in $\log 10$ space. Monthly decadal averages were used in the succession and trend analysis and were calculated in the same way using available data for each month. Unless otherwise indicated, decadal averages include data from the strong ENSO years 1997, 1998 and 1999 (see Sect. 2.5). Point data at stations of interest were calculated from monthly climatological imagery using the median value in a 1-degree box $(4 \times 4$ pixels from the $1 / 4$-degree resolution imagery, see Sect. 2.1) containing the station location.

\subsection{ENSO and anomaly calculations}

The Multivariable El Niño - Southern Oscillation (ENSO) Index (MEI, http://www.cdc.noaa.gov/people/klaus.wolter/ MEI/mei.html; Wolter and Timlin, 1998) was used to assess the influence of the state of El Niño and La Niña events on observed variables. The second half of 1997 and the first half of 1998 experienced a very strong El Niño, whereas the second half of 1998 and all of 1999 experienced a subsequent strong La Niña. Thus, the years 1997, 1998 and 1999 were designated strong ENSO years and, where indicated, were excluded from analyses, such as trend calculations. The available time-series consisted of 8 full years (2000-2007) without the strong ENSO years, and ten years and 4 months (Sep 1997-Dec 2007) with the strong ENSO years.

Temporal trends were computed for nine specific geographic regions with waters deeper than $200 \mathrm{~m}$ (based on NOAA ETOPO2 bathymetry sampled at $1 / 4$ degree resolution, see Sect. 2.3). The nine regions are outlined in Fig. 2.

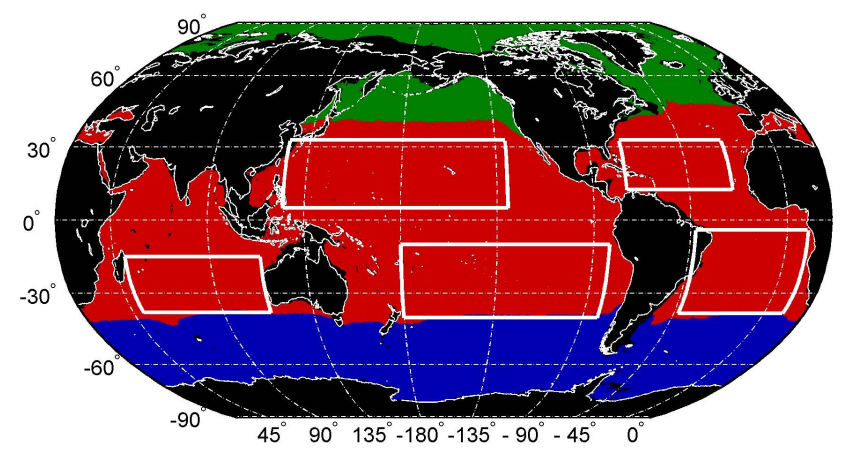

Fig. 2. Boundaries of the nine geographical regions considered in the present analysis. The five subtropical oligotrophic gyres are delineated with white lines; boundaries are after McClain et al. (2004). The global deep waters ( $>200 \mathrm{~m}$ depth, Global Region) are split into three sub-regions, namely Warm Ocean (red, $>15^{\circ} \mathrm{C}$ decadal average SST), North Hemisphere Cold Ocean (green) and South Hemisphere Cold Ocean (blue). See Tables 1 and 2 and Sect. 2.5. Robinson's projection centered on $160^{\circ} \mathrm{W}$ is used here and for all subsequent maps.

The Global Region encompassed all valid data. The mean 15C SST isotherm was used to delineate the Warm Ocean where waters were on the average warmer than $15 \mathrm{C}$, the North Hemisphere (NH) Cold Ocean, and South Hemisphere (SH) Cold Ocean following Behrenfeld et al. (2006). Finally, the five oligotrophic subtropical gyres (STG's) of the World Ocean comprised the final five regions considered following the definitions in McClain et al. (2004).

Monthly anomalies were calculated by subtracting each pixel's monthly decadal average from the monthly value. Spatial means of the anomalies in the 9 regions defined above were then calculated, weighting each pixel's value by its area (a function of latitude). The months of May, June, July and August were excluded from the time series for the SH. Cold Waters region and the months of November, December, January and February were excluded from the NH Cold Waters region. This was necessary because due to very low sun altitudes at high latitudes during the respective hemisphere's winter, the valid data areal coverage during winter months decreased to less than $67 \%$ of the maximum coverage during the summer months. Additionally, few data are available there to build the monthly composites during these periods. To calculate trends, an ordinary least squares linear regression of the monthly anomaly on time for the period 2000 through 2007 was performed and the regression slope was considered the trend. The p-value of the regression and the slope interval's crossing of the zero line were used to assess whether the computed trends were statistically significant (Walpole et al., 1998). 


\section{Results}

\subsection{Validation of PFT retrievals using global in-situ HPLC phytoplankton pigment concentration determinations}

Validation regressions of PFT's derived from in-situ HPLC pigments (Sect. 2.3) and PFT's derived from matched up SeaWiFS data using the PSD method yielded $R^{2}=0.340$ for picoplankton (Fig. 3a) and $R^{2}=0.415$ for microplankton (Fig. 3c). Validation results were worse for nanoplankton $\left(R^{2}=0.106\right.$; Fig. $\left.3 \mathrm{~b}\right)$. Picoplankton satellite estimates tend to have an exaggerated range, very low $\%$ picoplankton volumes in productive waters and very high \% picoplankton in oligotrophic waters. This results in a slope significantly different from unity. Both slope and $R^{2}$ values are better for the microplankton PFT validation regression. The poor performance for the nanoplankton PFT was expected given the smaller range of variability in percent nanoplankton-sized particle contribution inherent in the PFT definition functions (Fig. 1; Sect. 2.2). Namely, the SeaWiFS nanoplantkon retrievals showed a cluster of results near 50\%, which was not seen in the in-situ observations. Further assessment of the validation is given in Sect. 4.2.

\subsection{Global decadal averages of the PFT's and related parameters}

Monthly decadal averages of SST (Fig. 4a) and chl (Fig. 4b) revealed the general global-scale first-order inverse correlation, driven by the fact that warmer, stratified waters are nutrient poor, whereas mixed, nutrient-rich, upwelled waters are colder. The global linear correlation coefficient between $\log 10(\mathrm{chl})$ and SST from the decadal average images of Fig. 3 was $r=-0.57$ (only locations deeper than $200 \mathrm{~m}$ were considered). The most prominent feature in the global SST distribution was the latitudinal dependence, superimposed on which are permanent circulation features such as the cold California Current, the Humboldt Current off of Chile and the Benguela Current off of Africa, as well as the Equatorial Upwelling regions; warm currents such as the Gulf Stream and the Kuroshio Current were also evident. In most cases the chl decadal average (Fig. 4b) had correspondingly high chl at the colder, upwelling-associated locations. The most prominent features in the chl decadal average were the five oligotrophic subtropical gyres of the World Ocean - the North and South Atlantic (NA and SA STG's), the North and South Pacific (NP and SP STG's) and the South Indian gyres (IO STG), respectively. Mean chl in the gyres does not rise above $0.1 \mathrm{mg} \mathrm{m}^{-3}$, and was actually less than $0.03 \mathrm{mg} \mathrm{m}^{-3}$ in the South Pacific subtropical gyre - the most oligotrophic area of the World Ocean (e.g. Bonnet et al., 2008). Other prominent features of the chl decadal average were the high chl, productive areas, such as the Eastern Boundary Currents, the North Atlantic Bloom area, the Equatorial Upwelling
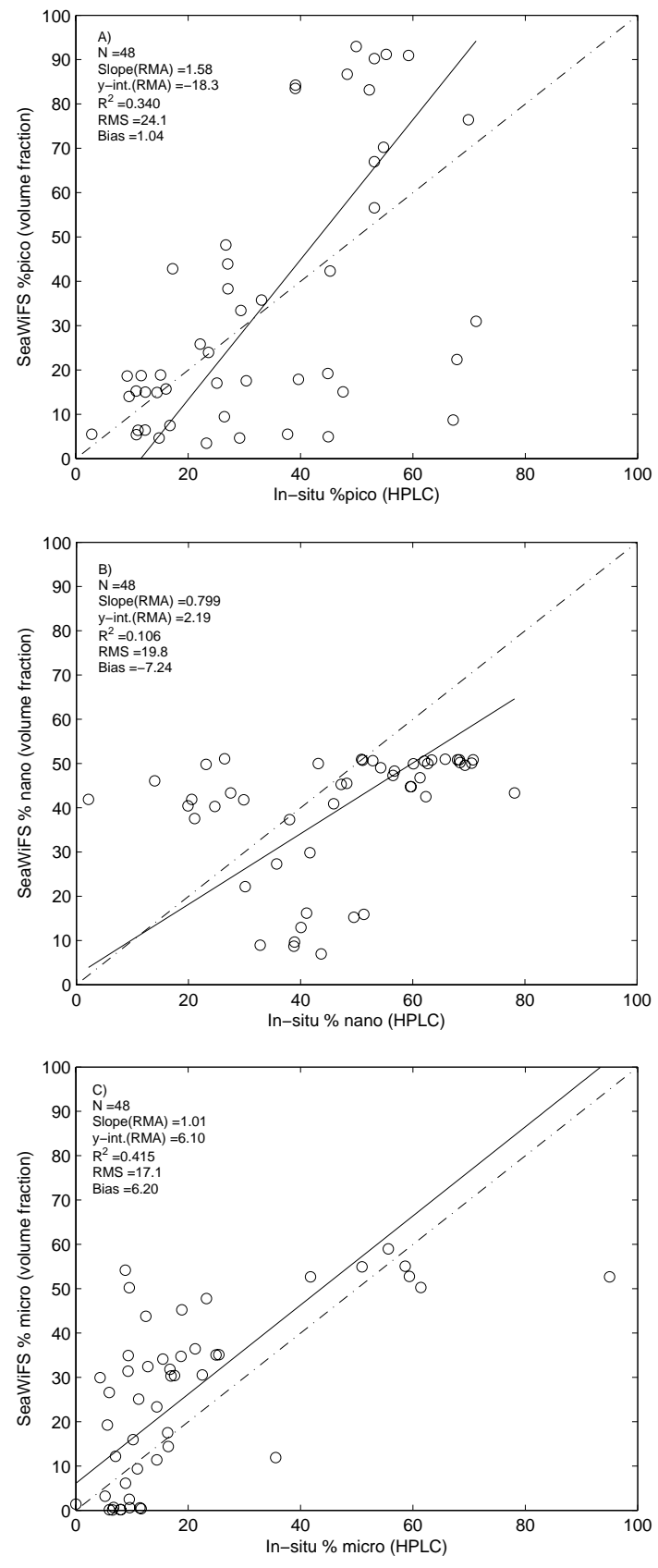

Fig. 3. PFT algorithm validation regressions for (A) percent picoplankton, (B) percent nanoplankton and (C) percent microplankton. The in-situ PFT's (x-axes) were calculated using the Vidussi et al. (2001) diagnostic phytoplankton pigment ratio method. Global HPLC surface data were matched to Level-3 daily SeaWiFS imagery in order to calculate a satellite PFT estimate using the PSD algorithm (y-axes). Type II regressions were used. RMS (Root Mean Square) and bias statistics are independent of the regression lines. 
A) AVHRR mean SST, ${ }^{\circ} \mathrm{C}$, (Jan. 1997 - Dec. 2007)

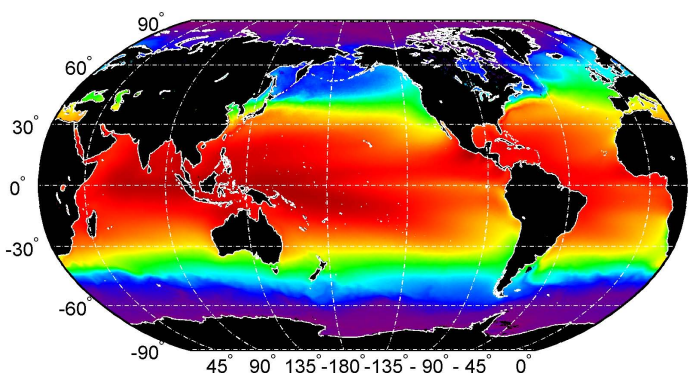

B) Mission mean of Chl (Sept. 1997 - Dec. 2007)

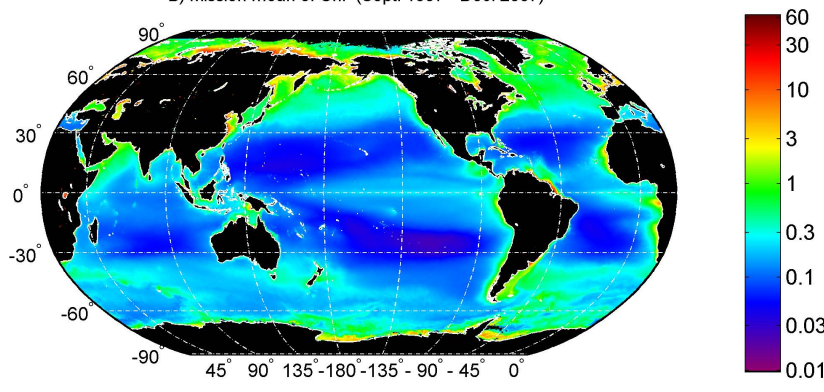

C) Mission mean of $\xi$ (Sept. 1997 - Dec. 2007)

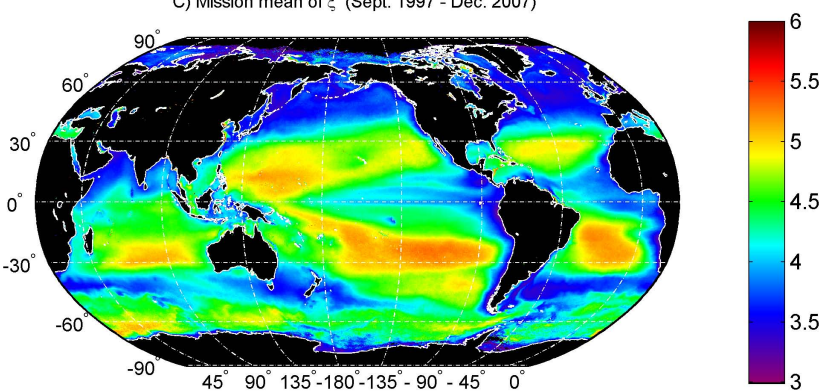

Fig. 4. (A) Mean global SST $\left({ }^{\circ}\right.$ C) (Sep 1997-Dec 2007) based on monthly AVHRR Pathfinder v 5.0 data; (B) SeaWiFS mission mean of chlorophyll-a concentration in $\mathrm{mg} \mathrm{m}^{-3}$ ( $\log 10$ color scale), and (C) SeaWiFS mission mean of the PSD slope, $\xi$, (unitless) as derived by the Kostadinov et al. (2009) algorithm.

zone, and coastal and high latitude areas in general. The global climatological spatial patterns of the power-law PSD slope, $\xi$, (Fig. 4c) exhibited marked inverse correlation to the $\log 10$ (chl) image ( $r=-0.88$ for waters deeper than $200 \mathrm{~m}$ ). Low-chlorophyll, low-productivity areas were characterized by high PSD slopes and vice-versa, suggesting that low productivity areas were associated with relative dominance of smaller particles and vice-versa, consistent with current understanding of oceanic ecosystems (e.g., Falkowski et al., 1998).

Monthly decadal averages of number concentrations of picoplankton-sized particles (Fig. 5a), nanoplanktonsized particles (Fig. 5b), and microplankton-sized particles (Fig. 5c) exhibited several notable global features (note that the same color scale is used for all size classes). First, for all size ranges, the oligotrophic gyres had the lowest particle abundances, transitional areas featured higher par-
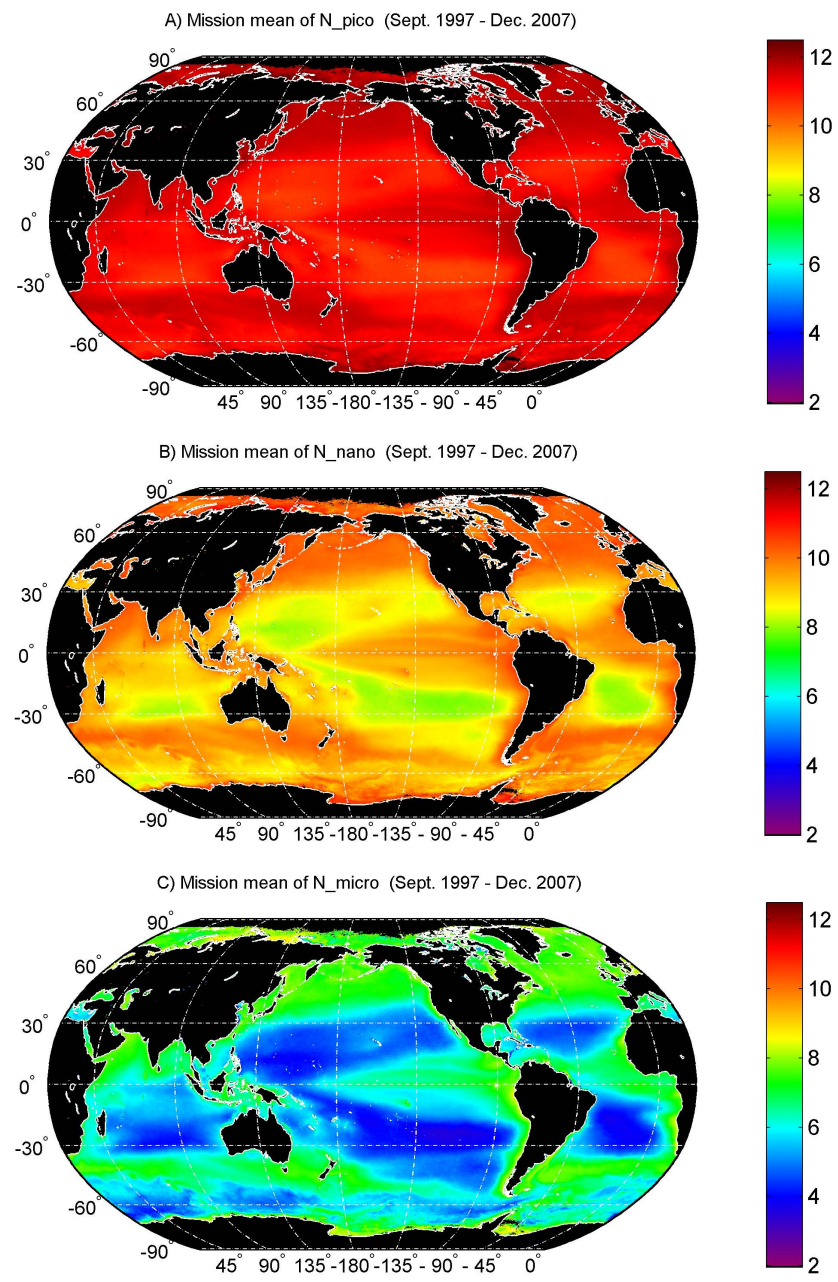

Fig. 5. SeaWiFS mission mean (Sep 1997-Dec 2007) maps of the number concentration (in particles per $\mathrm{m}^{3}$ of seawater in $\log 10$ space) of (A) picoplankton-sized particles $(0.5-2 \mu \mathrm{m}),(\mathbf{B})$ nanoplankton-sized particles $(2-20 \mu \mathrm{m})$, and (C) microplanktonsized particles $(20-50 \mu \mathrm{m})$. Number concentrations were calculated from the PSD parameters $\xi$ and $N_{0}$ (see Eq. 5 in Kostadinov et al., 2009).

ticle counts, whereas high productivity areas such as coastal, high latitude, Equatorial and upwelling regions were characterized by the highest particle abundances. Second, as expected, picoplankton-sized particles dominate everywhere numerically. Last, picoplankton-sized particle abundances varied comparatively little spatially $(<2$ orders of magnitude), nanoplankton-sized particle numbers varied more ( $>3$ orders of magnitude), while spatial variations in microplankton particle abundance were the largest ( $>6$ orders of magnitude) and microplankton-sized particles were practically absent from the subtropical oligotrophic gyres.

Volume concentrations and fractions are useful biogeochemical parameters because they are closely related to phytoplankton pigment and carbon biomass. The contribution made by picoplankton-sized particles $(0.5-2 \mu \mathrm{m}$ in diameter $)$ 
to the total volume concentration of phytoplankton-sized particles $(0.5-50 \mu \mathrm{m})$ was highest in the subtropical gyres, where it exceeded $80 \%$ in some places (Fig. 6a). Such high prevalence of small particles is indicative of very oligotrophic waters. Another band of high percent contribution of picoplankton-sized particles was found in the Southern Ocean at $\sim 60^{\circ} \mathrm{S}$; however the decadal average there was temporally biased (see below). In contrast to the spatial pattern of the contribution of picoplankton-sized particles, nanoplankton-sized particles $(2-20 \mu \mathrm{m})$ constituted about $50 \%$ of the particle volume in large transitional areas of the World Ocean, as well as high productivity areas (Fig. 6b). Finally, microplankton-sized particles only contributed substantially in the most productive areas of the World Ocean (Fig. 6c), rarely exceeding $40-45 \%$ of the phytoplanktonsized particle volume.

A map of the number of months available for the decadal averages of PSD slope and $N_{o}$ (Fig. 7a) reveals that retrievals for the high latitude seas were often unavailable due to low solar altitudes and/or seasonal ice cover. Even if SeaWiFS data were available, the retrieval of $b_{\mathrm{bp}}(\lambda)$ via Loisel et al. (2006) was often not reliable (see Kostadinov et al., 2009). This results in fewer than 80 months (out of 124) available poleward of $45^{\circ}$ latitude, indicating that the four winter months in the respective hemispheres were not sampled. This introduces a temporal bias in the decadal averages poleward of $45^{\circ}$, especially poleward of latitudes $>60^{\circ}$ when only about four months of the year were available. Thus, decadal averages and spatial means should be interpreted with caution when they include high latitude areas (See Sect. 2.5).

Monthly variability in chl, as measured by its standard deviation, was relatively low in the permanently stratified subtropics (where chl is low year-round), higher in the transitional and Equatorial Upwelling regions, and yet higher in areas which exhibit seasonal blooms, such as the North Atlantic, and coastal and high latitude areas (Fig. 7b). The standard deviation map for the percent contribution by picoplankton-sized particles (Fig. 7c) exhibited significant peaks at about $30-40^{\circ} \mathrm{N}$, slanted in a NE-SW orientation, and had a counterpart in the Southern Hemisphere (more zonally oriented in all three oceans). These areas exhibit strong seasonal cycles with associated winter deep mixing and strong summer stratification and oligotrophy (Longhurst, 2007), which explains the high variability in the picoplankton PFT contribution. There was a visual correspondence between the standard deviation maps for chl (Fig. 7b) and microplankton-sized particle percent contribution (Fig. 7d). There were also roughly zonal bands of high variability for all variables considered just north of the Equator in much of the Pacific and just south of the Equator in the Western Pacific and the Indian Oceans. As expected, the areas of the Indian Ocean affected by the seasonal blooms due to the Indian Monsoon exhibited high standard deviations for all three parameters (Fig. 7b-d). Finally, high standard deviations in
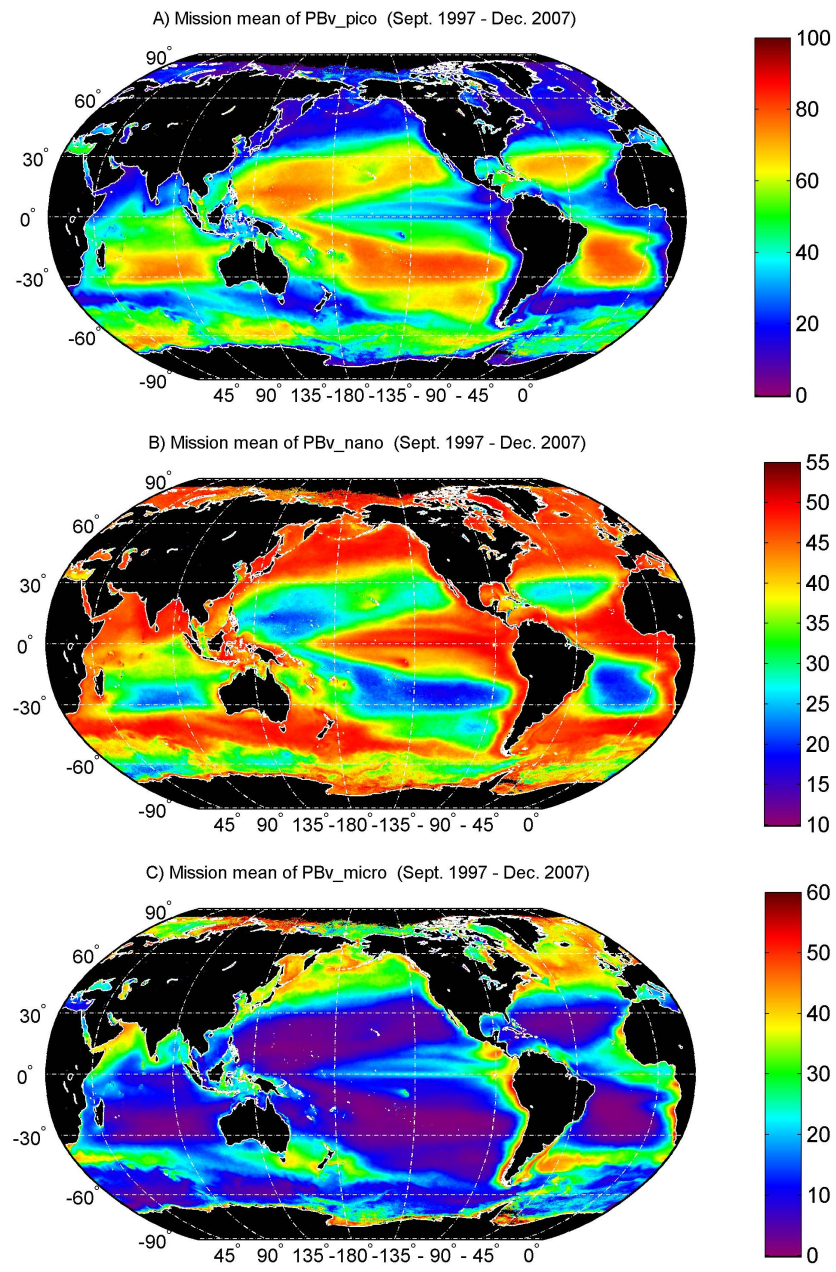

Fig. 6. SeaWiFS mission mean (Sep 1997-Dec 2007) maps of the PFT's: (A) the percent volume concentration contribution of picoplankton-sized particles $(0.5-2 \mu \mathrm{m}$ in diameter), (B) the percent volume concentration contribution of nanoplankton-sized particles $(2-20 \mu \mathrm{m})$, and $(\mathbf{C})$ percent volume concentration contribution of microplankton-sized particles $(20-50 \mu \mathrm{m})$. The percent contributions were calculated out of the total volume $(0.5-50 \mu \mathrm{m}$ diameter range) as a function of the PSD slope $\xi$ (Eq. 2; Fig. 1).

the Southern Ocean were indicative of strong seasonal cycles there as well, but should also be interpreted with caution because of the biased statistics (Fig. 7a). Interestingly, all main features remain similar when ENSO years were excluded from the analysis (using only data from Jan 2000 to Dec. 2007; not shown).

\subsection{Seasonal PFT succession at four well characterized sites}

The monthly decadal averages of PSD-based PFT's are expected to be useful for assessing global bloom dynamics and succession patterns. The development of a spring bloom and the concurrent rise of chl, for example, should be 

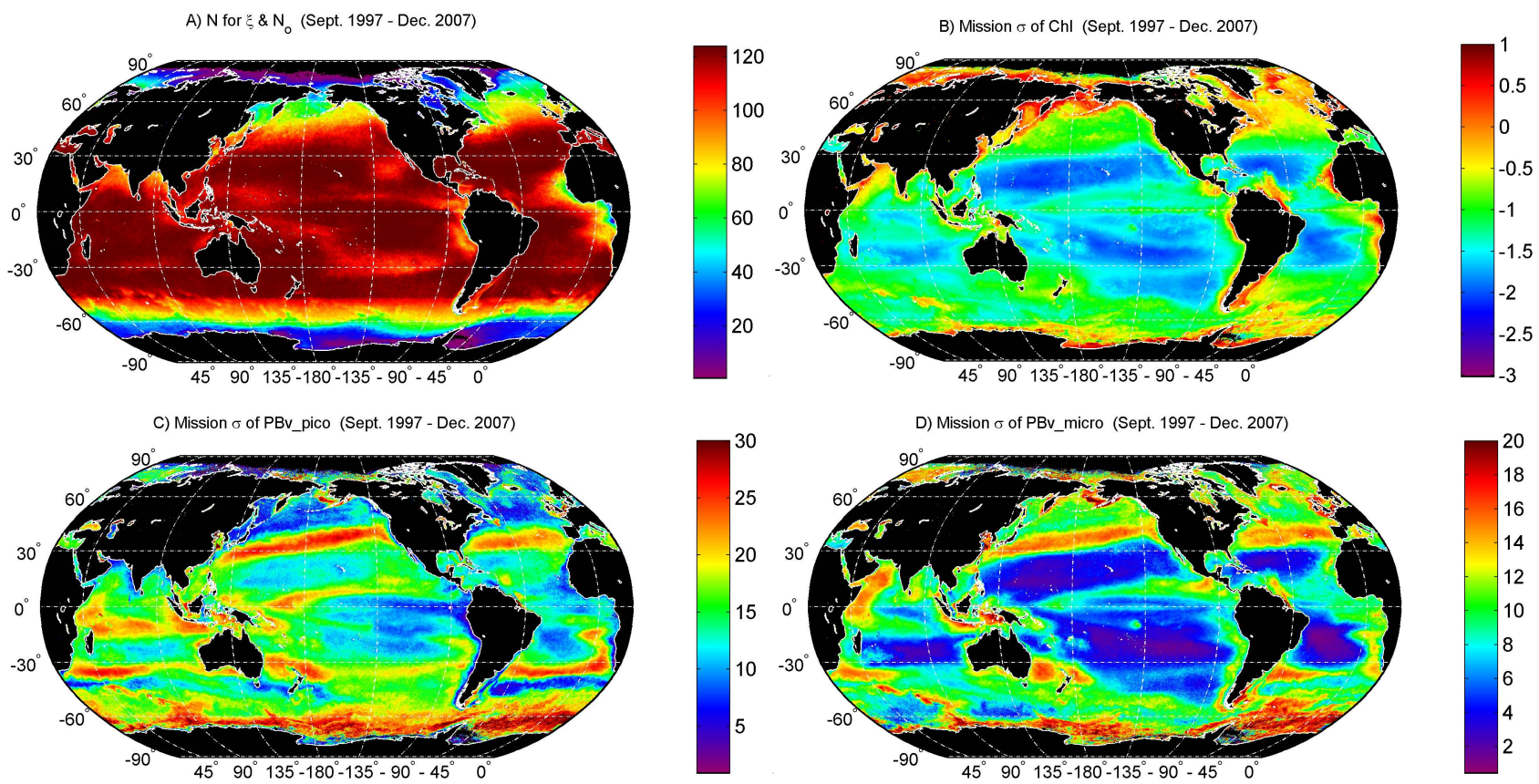

Fig. 7. (A) Map of the number of months of valid data used in the decadal averages computation for $\xi$ and $N_{0}$. Standard deviation maps for $(\mathbf{B}) \mathrm{Chl}\left(\mathrm{mg} \mathrm{m}^{-3}\right)$, calculated in linear space but shown on $\log 10$-based color scale, $(\mathbf{C})$ the \% picoplankton-sized particles of the total volume concentration and (D) the \% microplankton-sized particles of the total volume concentration.

accompanied by decreases in PSD slope and increases in the microplankton PFT contribution. Here, we choose to compare and contrast four well studied locations in the Northern Hemisphere, the site of the North Atlantic Bloom Experiment (NABE) and the Bermuda Atlantic Time Series (BATS) site in the North Atlantic and stations PAPA and ALOHA in the North Pacific.

The NABE site $\left(47^{\circ} \mathrm{N}, 20^{\circ} \mathrm{W}\right.$, Lochte et al., 1993) has captured the attention of early oceanographers with its pronounced spring/summer phytoplankton bloom, leading to it being used to define Sverdrup's critical depth hypothesis on the cause of these blooms (Sverdrup, 1953; Siegel et al., 2002). The station falls in Longhurst's (2007) North Atlantic Drift Province (NADR), part of the North Atlantic Westerly Winds Biome and is characterized by anomalously high winter wind stress and a "nutrient-limited spring production peak" (Longhurst, 2007). The NABE site showed a pronounced early summer phytoplankton bloom, exhibiting a chl peak in June of $\sim 0.8 \mathrm{mg} \mathrm{m}^{-3}$ (Fig. 8a). The bloom followed deep winter mixing as evident in the climatological SST time series (Fig. 8a), where annual temperature range exceeds $5^{\circ} \mathrm{C}$, consistent with observations of the entire region (Longhurst, 2007). Particle number concentration in the $0.5-50 \mu \mathrm{m}$ diameter range peaked in June and was strongly correlated with the seasonal cycle of chl. This indicates that NABE particle abundances were driven by bloom dynamics. As expected, the PSD slope seasonal cycle (Fig. 8a) was inversely correlated with the chl cycle, with a minimum in June when larger particles were relatively more dominant at the peak of the bloom. The overall variability in the PSD slope was not very large, however, leading to a relatively weak annual cycle of the percent contribution by the PFT's at the site (Fig. 8b). For example, microplankton volume contributions varied from about $30 \%$ in the winter to $\sim 45 \%$ in the June bloom peak. The $\%$ picoplankton had the opposite pattern. This was consistent with findings summarized in Longhurst et al. (2007) that diatoms were not necessarily the only or dominant population in the blooms.

Station PAPA $\left(50^{\circ} \mathrm{N}, 145^{\circ} \mathrm{W}\right.$, Harrison (2002)) falls within the Eastern Pacific Subarctic Gyre (PSAG-E) province of Longhurst et al. (2007), part of the Pacific Westerly Winds Biome. Like the NABE station, its main characteristic is a nutrient-limited spring production peak. However, the annual cycles discussed above were fundamentally different at PAPA (cf. Fig. 8a/b and 8c/d). Satellite chl patterns revealed little seasonal variability, with a peak in September, rising to $0.4 \mathrm{mg} \mathrm{m}^{-3}$ from $\sim 0.2 \mathrm{mg} \mathrm{m}^{-3}$, after the summer peak in SST's (Fig. 8c). A corresponding rise in number concentration followed chl, although not as closely as found for the NABE site. Moreover, the particle number concentration rose to levels similar to those observed at NABE. Longhurst's (2007) PAPA depth-integrated productivity curve showed a spring peak and was decoupled from chl, unlike NABE. Interestingly, the PSD slope exhibited larger variability than at NABE and an opposite correlation is found with chl and number concentration as compared to station NABE or global scales. The behavior of the PSD slope dictates the relative contributions of the PFT's (Eq. 2). 

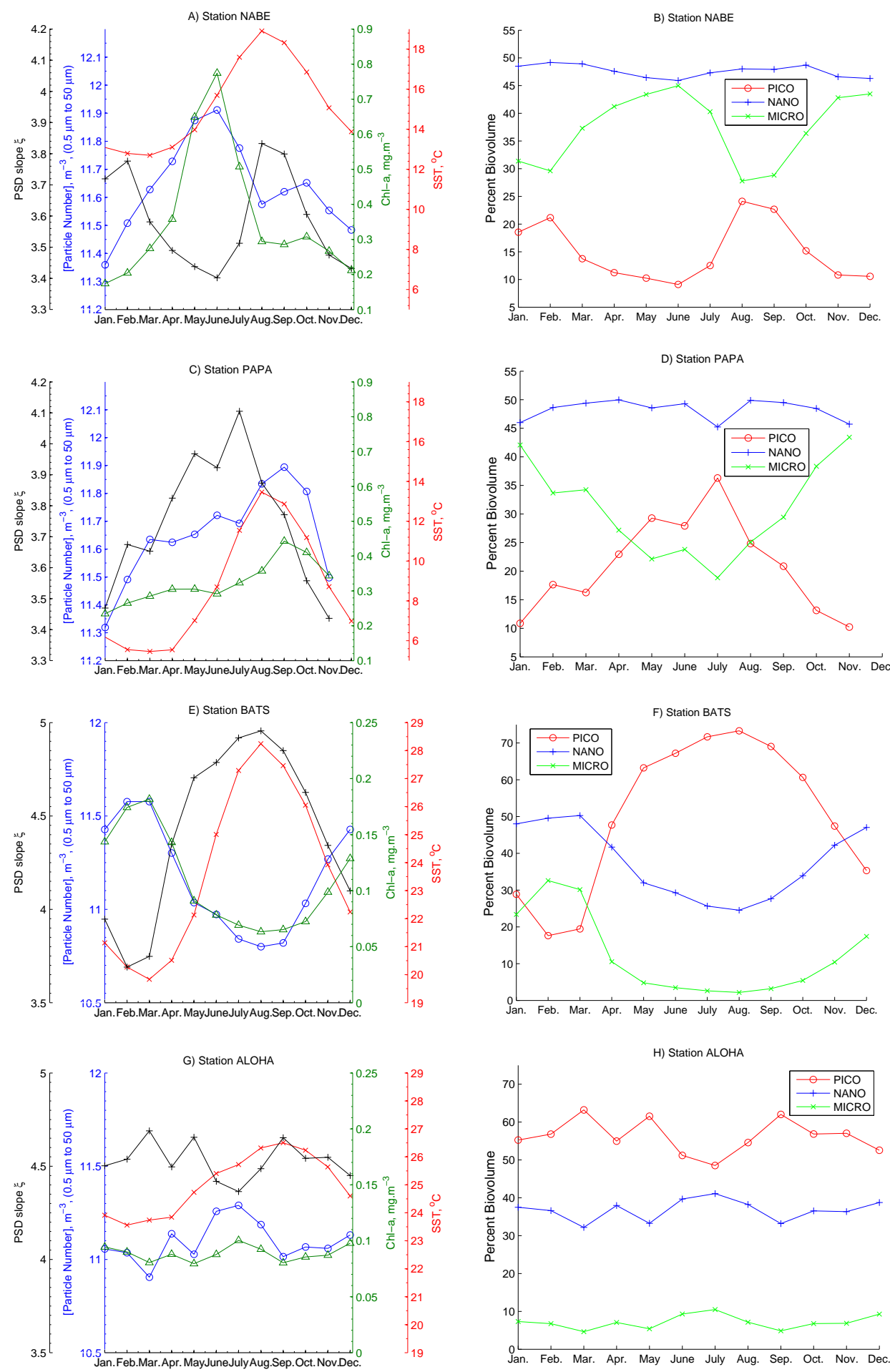

Fig. 8. Monthly decadal average time-series of PSD slope (black), phytoplankton-sized ( 0.5 to $50 \mu$ in diameter) particle number concentration (blue), SeaWiFS Chl (green), and AVHRR SST (red), plotted on the left panels and SeaWiFS-derived PFT's, \% picoplankton (0.5 to $2 \mu \mathrm{m}), \%$ nanoplankton (2 to $20 \mu \mathrm{m})$, and \% microplankton (20 to $50 \mu \mathrm{m}$ ) (right panels) for four temperate and subtropical North Hemisphere sites: (A and B) North Atlantic Bloom Experiment (NABE), nominally at $47^{\circ} \mathrm{N}, 20^{\circ} \mathrm{W}$; (C and D) the Northeastern Pacific Station PAPA, nominally at $50^{\circ} \mathrm{N}, 145^{\circ} \mathrm{W} ;(\mathbf{E}$ and $\mathbf{F})$ the Bermuda Atlantic Time Series (BATS) station, nominally at $31^{\circ} 50^{\prime} \mathrm{N}, 64^{\circ} 10^{\prime} \mathrm{W}$, and $(\mathbf{G}$ and H) station ALOHA near the Hawaiian Islands, nominally at $22^{\circ} 45^{\prime} \mathrm{N}, 158^{\circ} 00^{\prime} \mathrm{W}$. The SeaWiFS monthly decadal averages are based on Sep 1997 through Dec 2007. AVHRR average was based on the complete years 1997 through 2007 . The median of all valid pixels from each month's decadal average image in a 1-degree box containing the respective station was used. 
Although nanoplankton volume contributions were relatively constant at 45 to $50 \%$, the microplankton peak was found in the winter, far from the chl and number concentration peaks (Fig. 8d). Longhurst (2007) attributed these large differences to disparate stratification regimes, e.g. the depth of winter mixing was much shallower at PAPA than at NABE (Whitney and Freeland, 1999). Others cited the HNLC character of the area and attributed these differences to iron limitation (Boyd and Harrison, 1999). Compared with station NABE, picoplankton-sized particles exhibited higher dominance and this result is consistent with Boyd and Harrison (1999) (see their Fig. 4).

Comparison of the two subtropical sites, BATS $\left(31^{\circ} 50^{\prime} \mathrm{N}\right.$, $64^{\circ} 10^{\prime} \mathrm{W}$, Siegel et al., 2001) in the Atlantic (Fig. 8e/f) and ALOHA ( $22^{\circ} 45^{\prime} \mathrm{N}, 158^{\circ} 00^{\prime} \mathrm{W}$, Karl et al., 1996) (Fig. 8g/h) in the Pacific near the Hawaiian Islands revealed large differences between the two sites. Station BATS exhibited strong seasonal excursions of SST, and almost a 4-fold excursion in chl with a peak in March. BATS falls in the Western North Atlantic Subtropical Gyral Province (NAST-W) of Longhurst (2007) and is characterized by winter-spring production peak with nutrient limitation. The cycles of the PSD slope were very strong, accompanied by a strong and inverse correlation with particle abundance (Fig. 8e). Thus, the seasonal cycles of PFT's were pronounced and well related to chl, where high chl in March was associated with up to $30 \%$ microplankton volume contributions which then fell to almost $0 \%$ in the late summer oligotrophic period when picoplankton-sized particles contributed more than $70 \%$ of the volume concentration.

In contrast to the strong seasonal cycles at BATS, the station ALOHA record (Fig. 8g/h) was characterized by very little seasonal variability in all parameters. The excursion of SST's was less than $3^{\circ} \mathrm{C}$, as compared to about $8^{\circ} \mathrm{C}$ at BATS, chl variability was minimal $\left(\sim 0.1 \mathrm{mg} \mathrm{m}^{-3}\right)$, and the PSD slope was generally high exhibiting little variability. Total particle abundances also showed little variability. As a result of the small PSD slope variability, PFT's did not vary much (Fig. $8 \mathrm{~h}$ ). The volume contribution by picoplankton was consistently high at roughly $55 \%$, indicating that ALOHA is the most oligotrophic site of all four stations discussed.

\subsection{Meridional views of PFT seasonal succession}

Meridional-time transects along $30^{\circ} \mathrm{W}$ in the Atlantic Ocean for chl, particle abundance and the PFT's (Fig. 9) reveal space-time dependencies for all parameters. The oligotrophic subtropical gyres are clearly evident, where chl and particle abundances were both low and picoplanktonsized particles dominate. More productive waters were found along the Equator and just north of it, exhibiting weak seasonality generally consistent with the timing of the development of the North Equatorial Countercurrent and suggesting possible influence of Amazon Outflow on productivity (DelVecchio and Subramaniam, 2004; Subramaniam et al.,
2008). The observation of reduced salinity as far out as $8^{\circ} \mathrm{N}$, $35^{\circ} \mathrm{W}$ in late summer - early fall (Ternon et al., 2000) is also consistent with this interpretation. High productivity waters were found in all regions poleward of the subtropical gyres (Fig. 9), with strongest seasonality observed between 35 and 45 degrees latitude in both hemispheres. The progressively later timing of maximum chl, i.e. the poleward propagation of the peak of the North Atlantic spring bloom, can be clearly followed between $35^{\circ} \mathrm{N}$ and about $55^{\circ} \mathrm{N}$. This maximum in chl occurred in March for $35^{\circ} \mathrm{N}$, and in JulyAugust for $55^{\circ} \mathrm{N}$, giving a mean bloom progression rate of $\sim 16 \mathrm{~km} /$ day. Examination of the corresponding percent microplankton maxima yielded the same result. However, some differences between the chl and the PFT based estimates emerged, e.g. PFT-based maxima for microplanktonsized particles occurred a month earlier at $\sim 40-45^{\circ} \mathrm{N}$ and 2-3 months later for some latitudes near $55^{\circ} \mathrm{N}$, as compared to the chl-based maxima. Caution should be exercised in interpreting winter PFT data at higher latitudes, however (Sect. 2.5). The high-latitude South Atlantic is also characterized by seasonally productive waters; however to a lesser extent than the North Atlantic.

A transect along $140^{\circ} \mathrm{W}$ (Fig. 10) reveals largely similar spatio-temporal patterns in the Pacific although there were several important differences as compared with the Atlantic. The most notable differences were the considerably lower chlorophyll concentration and lower percent contributions by large particles to the total particle volume. Although particle abundances were similar, volume concentrations in the 0.5 to $50 \mu \mathrm{m}$ range were consistently lower regionally near station PAPA as compared to station NABE (not shown). This result is consistent with a smaller North Pacific bloom as compared to the North Atlantic. As noted above, the subpolar NE Pacific is known as an HNLC region (Boyd and Harrison, 1999), and the lack of the expected correlation between the PSD slope and chl (cf. Fig. 8c/d) may be a clue to a different ecosystem compared with the North Atlantic. Another interesting feature of the Pacific transect was the narrow band of higher productivity at $10^{\circ} \mathrm{S}$. The $140^{\circ} \mathrm{W}$ transect intersects the Marquesas Islands at that location, and the higher productivity is due to the island mass effect (Signorini et al., 1999).

Importantly, station monthly time series (Fig. 8) and meridional-time transects (Figs. 9 and 10) demonstrate the utility of independent PFT estimates in assessing bloom dynamics and succession. Consistent with current understanding of oceanic ecosystems, generally as a bloom progresses, increases in chl are accompanied by increases in particle abundance and increased volume contribution by larger particles, such as microplankton. This is due to increased biomass of large species such as diatoms, typical of early bloom stages. As the bloom peaks in biomass and later decays, the ecosystem returns to more oligotrophic status, with a smaller particle abundance and a larger contribution by picoplankton. These patterns are most evident when following a given 

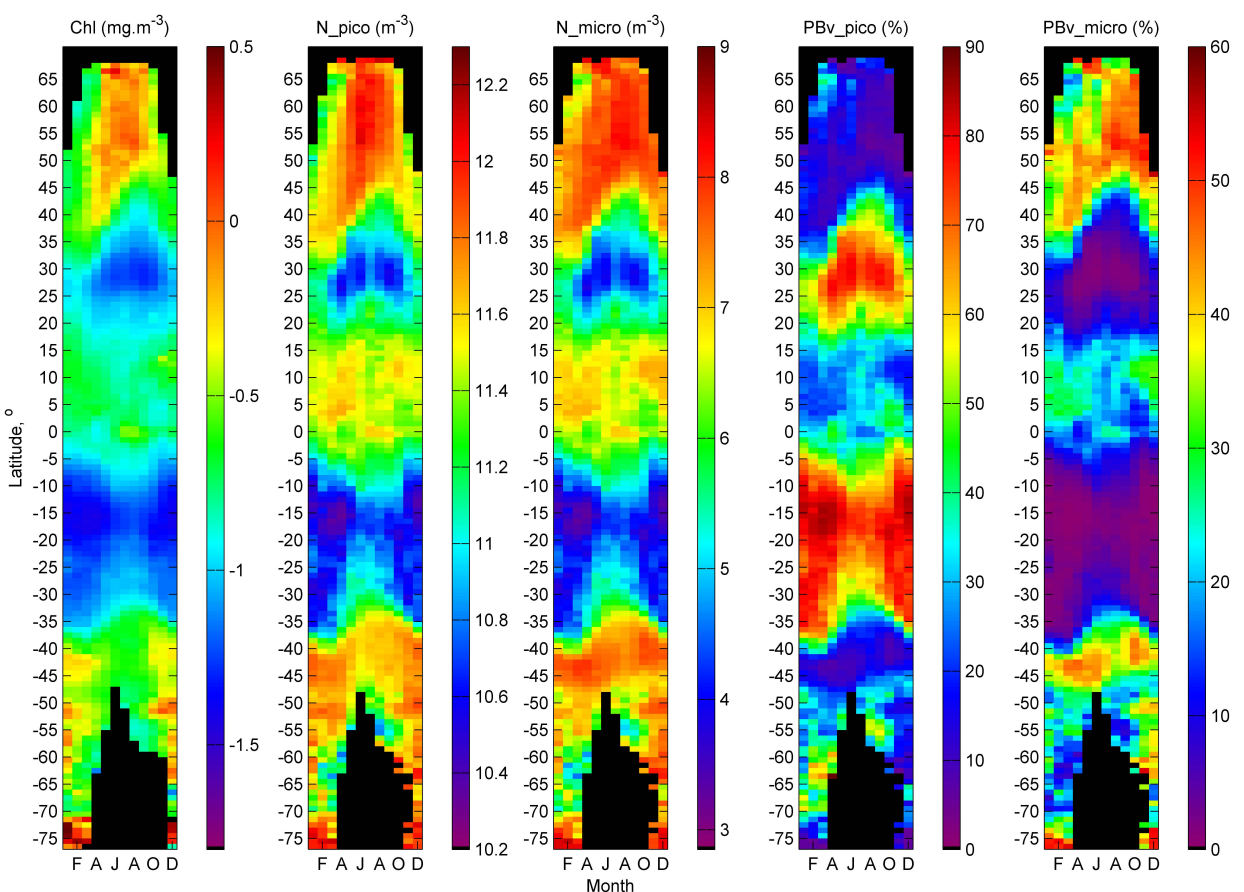

Fig. 9. Meridional-time transects along $30^{\circ} \mathrm{W}$ of SeaWiFS OC4v4 Chl (leftmost panel, color scale in log 10 space) and several relevant SeaWiFS PSD algorithm products (from left to right, particle number concentration in the picoplankton $(0.5$ to $2 \mu \mathrm{m}$ in diameter) and microplankton $(20-50 \mu \mathrm{m})$ size ranges, and percent particle volume due to picoplankton and microplankton. The resolution is 1 degree by 1 month; values for each month were obtained by taking the spatial mean of a $4 \times 4$ pixel box from the monthly decadal average images. Color scales are in $\log 10$ space for the first three panels and linear for the last two.
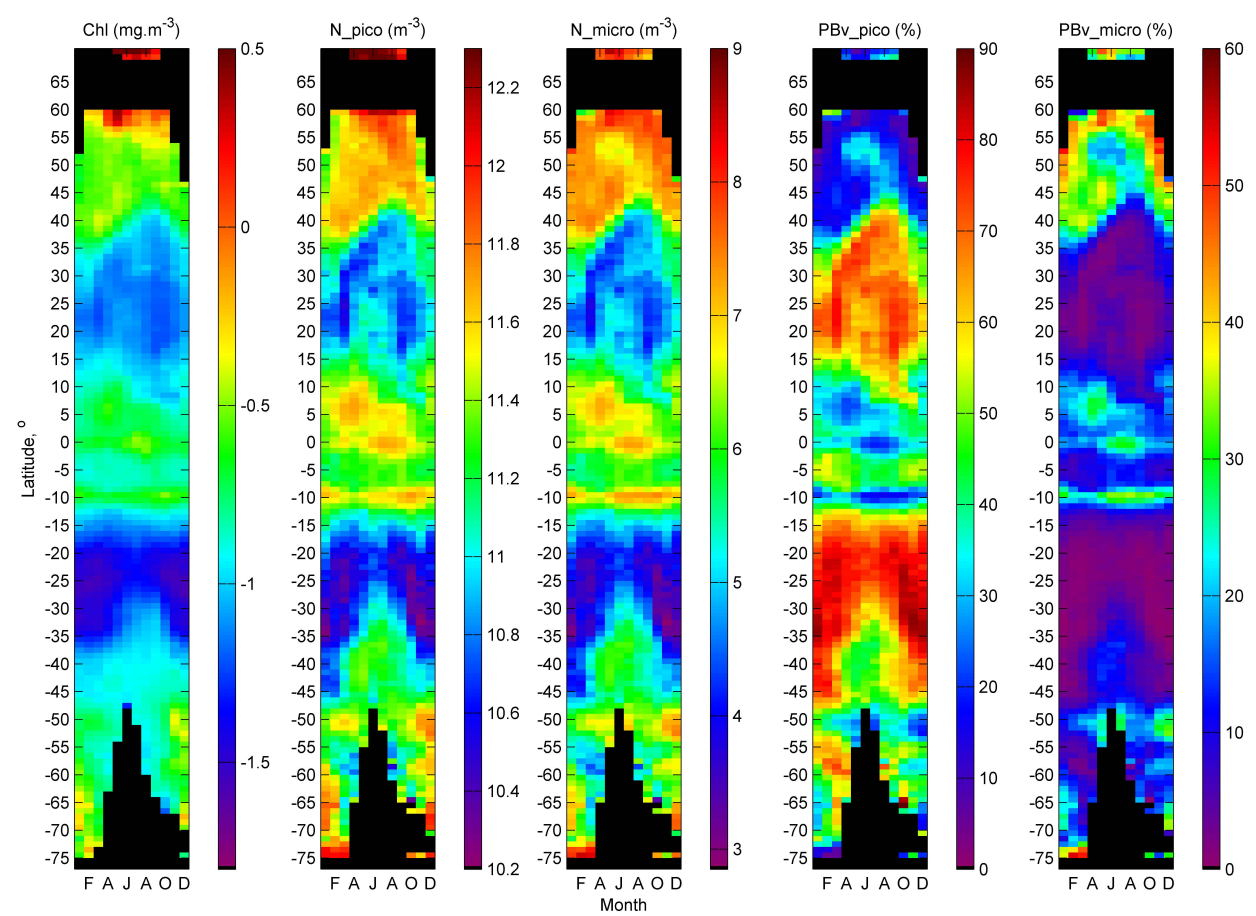

Fig. 10. Meridional-time transects along $140^{\circ} \mathrm{W}$ of SeaWiFS OC4v4 Chl (leftmost panel) and several relevant SeaWiFS PSD algorithm products from left to right, particle number concentration in the picoplankton $(0.5$ to $2 \mu \mathrm{m})$ and microplankton $(20-50 \mu \mathrm{m})$ size ranges, and percent particle volume due to picoplankton and microplankton. The resolution is 1 degree by 1 month; values for each month were obtained by taking the spatial mean of a $4 \times 4$ pixel box. Color scales are in $\log 10$ space for the first three panels and linear for the last two. 
latitude through time in the region of the North Atlantic Bloom or the BATS station (horizontal in Fig. 9). In spite of the general agreement between the PSD-derived PFT's and chl, they do supply complementary information. Correlations of the PFT's and chl can be used to assess the overall character of the ecosystem (e.g. the NABE vs. PAPA comparison above). Further, independent PSD/PFT and chl data could be used to assess physiological state and productivity (e.g., Behrenfeld et al., 2005, 2008) as well as to potentially partition productivity to different size classes. Uitz et al. (2010) detail a method to achieve this by using satellite chl observations and HPLC-based parameterizations.

\section{Discussion}

\subsection{General discussion of the PFT algorithm}

The retrieval of phytoplankton functional types proposed here is fundamentally different from comparable approaches (see Sect. 4.2) in that it uses information contained in the particulate backscattering spectrum to estimate the contributions that PFT's make to the total particle volume. The method relies on integration of volume concentrations from the parameters of a retrieved power-law PSD (Eq. 2), making PFT estimates sensitive to the size range over which the PSD is integrated. The limits chosen here $(0.5$ to $50 \mu \mathrm{m}$ in diameter) yield realistic results and are appropriate for our proof-of-concept study on global scales. A sensitivity analysis to these limits shows picoplankton contributions typically decrease by about $17 \%$ and nanoplankton increase by about $15 \%$ as the lower limit of integration is changed from 0.2 to $0.5 \mu \mathrm{m}$ for a range of PSD slopes. For low values of the PSD slope, microplankton increase by about $30 \%$ and nanoplankton decrease accordingly when the maximum limit of integration is changed from 50 to $200 \mu \mathrm{m}$. Conversely for low PSD slopes, sensitivity to the lower limit is very small $(<5 \%)$; while for high PSD slopes, sensitivity to the upper limit is small $(<5 \%)$. Further work is needed to assess the sensitivity to these limits in detail and possibly study the feasibility of operational choice of dynamic ranges regionally. For example, decreasing the lower limit to $0.2 \mu \mathrm{m}$ would encompass almost all living matter in the ocean (e.g. Clavano et al., 2007) and be consistent with the operational definition of dissolved vs. particulate matter, which would be important in oligotrophic areas; whereas using sizes as large as $200 \mu \mathrm{m}$ may be appropriate in eutrophic areas. Additionally, the retrievals of the PSD itself were constructed by assuming a finite PSD with stochastically varied size limits, however the propagated uncertainty to the PFT's is minimal (see below).

The present approach for assessing PFT's also makes implicit assumptions of the nature of the particle assemblage. Particles that backscatter light include not only phytoplankton but heterotrophic bacteria and eukaryotes, detritus, minerogenic particles and even bubbles. There is consid- erable uncertainty as to the relative contribution of the different sources to bulk backscattering (Stramski et al., 2004; Dall'Olmo et al., 2009) which include particles smaller than the PFT size range considered here. Further, in interpreting particle volume fractions as PFT proxies, it is assumed that the total particle assemblage covaries with the living phytoplankton portion, in reasonably similar proportions in all size ranges, so that the ratio in Eq. (2) is representative of the contribution by the respective phytoplankton size group. Compared to the Case I assumption of bio-optics (Smith and Baker, 1978; IOCCG, 2000; Siegel et al., 2005; Kostadinov et al., 2007), the assumption made here is more constraining and further investigation is necessary to fully understand its applicability, especially in coastal waters where terrigenous and minerogenic contributions to the particle assemblage are probable. Accordingly, if this assumption is violated, for example by having a river plume as a source of minerogenic particles that influence backscattering significantly, the calculated PFT's will have a significant error. Other sources of uncertainty are also expected to be higher in coastal waters (Kostadinov et al., 2009).

Uncertainties in the PFT retrievals are propagated from uncertainties in the underlying PSD retrievals, which have both endogenous sources (due to Mie model parameter choices) and hard-to-quantify exogenous sources due to input data error, inappropriate assumptions, etc. Since the evaluation of PFT's via Eq. (2) does not involve the differential abundance at the reference diameter $\left(N_{0}\right)$, associated endogenous uncertainty levels are very low in most of the ocean, reaching a maximum value of $\sim 7 \%$ in coastal and high productivity areas (one standard deviation for percent microplanktonsized particles evaluated for a single month, Kostadinov et al., 2009). These low uncertainty levels are an encouraging result, but we emphasize that this is an estimate of only the endogenous uncertainty, not a total error estimate. Additionally, any systematic error will be overlooked in such an estimate. Quantifying the total uncertainty without extensive empirical in-situ validation is not trivial. We stress the continued need for reliable and systematic global in-situ observations of oceanic PSD's and ecosystem structure and function. In particular, it is imperative that extensive data sets be collected that include concurrent high quality measurements of chl, particle size distributions, HPLC pigments, particulate organic carbon (as well other useful parameters, such as flow cytometry and microscopic observations) and absorption and backscattering coefficients and remote-sensing reflectance in order to improve PFT algorithms such as the one proposed here and address issues with their validation as are outlined in the following section. 


\subsection{Validation of the PFT algorithm and comparison to existing approaches}

Validation of the PSD-based PFT algorithm using phytoplankton pigment concentration ratios yielded similar performance for the picoplankton and microplankton PFT's $\left(R^{2}=0.340\right.$ and 0.415 , respectively) and a worse $R^{2}=$ 0.106 for nanoplankton (Fig. 3). The worse performance for nanoplankton was expected (Sect. 3.1) and is likely due to the PSD power-law model chosen and the limits of integration, and not necessarily a real feature of oceanic ecosystems. Validation of the PSD slope itself resulted in satisfactory, though clearly not excellent, comparisons (Kostadinov et al., 2009).

There are many reasons for differences between the in-situ phytoplankton pigment-based and satellite PSD-based PFT estimates. Various reasons why a field measurement can differ substantially from a satellite-derived determination due to the large differences in spatio-temporal scales of sampling between the satellite and the in-situ sample are detailed elsewhere (Bailey and Werdell, 2006; IOCCG, 2007; Kostadinov et al. (2009). Further in spite of the existence of a very large data set of in-situ HPLC samples, it was hard to obtain unique valid match-ups ( $N=48$ in Fig. 3). Importantly, the HPLC method of quantifying phytoplankton functional types via diagnostic pigment ratios is fundamentally different from the PSD-based approach. The phytoplankton pigmentbased assessments only approximately correspond to fixed size classes (Vidussi et al., 2001); therefore the diagnostic pigment estimates of the PFT's cannot be considered "true values" in this validation; thus we note that the term "validation" is used loosely here. Also, physiological processes such as photoadaptation are expected to affect the pigment composition but not necessarily the particle abundances and sizes. Finally, it should be emphasized that the PFT algorithm has not been constrained or tuned. We also emphasize the need for additional validation and inter-comparison of this and other existing PFT algorithms, ideally with extensive in-situ data sets, as suggested in Sect. 4.1.

Next, two existing satellite PFT retrieval approaches were compared to the PSD method proposed here. Comparisons were performed for picoplankton and microplankton only, given the unsatisfactory validation results for nanoplankton contribution (Fig. 3) and its small modeled variability for much of the ocean (Fig. 1). First, the method of Alvain et al. $(2005,2008)$ (referred to as the Alvain et al. (2008) method from here on) was considered; it uses second-order effects on the shape of SeaWiFS $L_{\mathrm{wN}}(\lambda)$, normalized to a reference shape for a given chl, with co-located in-situ diagnostic phytoplankton pigments observations in order to construct a classification scheme, categorically assigning each pixel to one of six classes. Thus, direct comparison with the PFT's defined here was not possible and their classes were grouped according to size to match our designation of picoplankton (their Prochlorococcus and Synechococcus), nanoplankton (their nanoeukaryotes, Phaeocysitis-like and
Coccolithophores), and microplankton (their diatoms). January (Fig. 11a) and July (Fig. 11b) monthly SeaWiFS decadal averages were compared, using only observations in waters deeper than $200 \mathrm{~m}$. January comparisons reveal that areas classified as picoplankton-dominated by Alvain et al. (2008) were also described as picoplankton-dominated by the PSD approach with only $\sim 10 \%$ contribution by microplankton on average; however, Alvain et al. (2008) microplankton pixels were characterized by very similar picoplankton and microplankton contributions by the PSD method. In contrast, July climatological comparisons were excellent on global scales (Fig. 11b), namely pixels classified as picoplankton or microplankton by Alvain et al. (2008) were also classified accordingly by the PSD PFT method. The difference in comparisons between January and July may be due to spatial difference in coverage (See Sect. 2.5) and to the particular status of the Southern Ocean, which was found to be dominated by nanoplankton even for high chl and was treated separately by Uitz et al. (2006) (cf. their Figs. 6 and 9).

Second, the PSD-based PFT retrievals were compared to the algorithm of Uitz et al. (2006), whose classification is based on a global HPLC data set of diagnostic pigments, used to parameterize PFT's as a function of satellite observations of chl. The estimates of Uitz et al. (2006) used here were calculated from the SeaWiFS mission mean and the PFT's are expressed as a percent contribution to the integrated chl in a depth horizon from the surface to 1.5 times the euphotic layer depth. Uitz et al. (2006) used the same three classes as the PSD-based approach, so that direct comparisons are possible using bivariate histograms of the PSDbased PFT images vs. the corresponding Uitz et al. (2006) image (Fig. 12). The histogram for picoplankton (Fig. 12a) exhibited a large number of pixels where the correspondence is quite good, with three large vertical excursions where the Uitz et al. (2006) mean map had low values and the PSDbased approach had high values. The rightmost excursion (highest \% pico values) was due to the oligotrophic gyres, where the PSD-based estimates reached $80 \%$ and the Uitz et al. (2006) approach did not exceed 50\%. The other two excursions were due largely to Southern Ocean waters, where, as pointed out earlier, there are peculiarities and a portion of this region was treated differently in the Uitz et al. (2006) classification. Microplankton comparisons (Fig. 12b) exhibited a fairly good correspondence, with the exception of an excursion where the Uitz et al. (2006) mean map attributed particle volume to microplankton and the PSD approach did not (due to the Southern Ocean again), and an underestimation of \% microplankton of the PSD-based approach compared to Uitz et al. (2006) due to the oligotrophic gyres. Among other reasons, comparison with the classification of Uitz et al. (2006) may have resulted in discrepancies because the PSD-based PFT calculation is based on surface and nearsurface backscattering, and their approach is based on a $1.5 \mathrm{x}$ photic-zone integrated chl parameterization. 

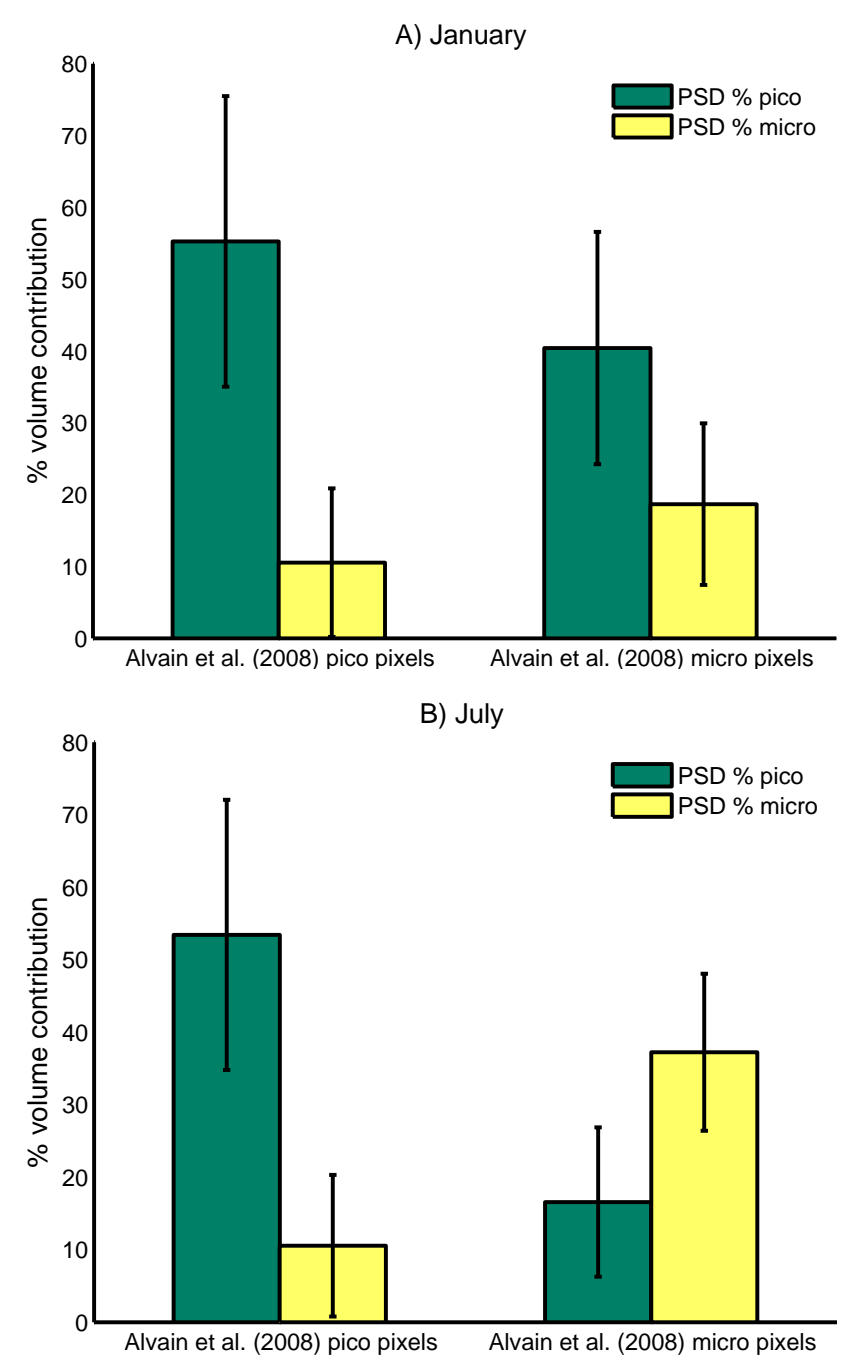

Fig. 11. Comparison of the $L_{\mathrm{wN}}(\lambda)$-based PFT method of Alvain et al. (2008) with the PSD-based PFT method presented here. The January (A) and July (B) global SeaWiFS decadal averages at $1 / 4$ degree resolution were used for the comparison, considering only pixels deeper than $200 \mathrm{~m}$. The size classes of Alvain et al. (2008) were grouped to match our three PFT's (picoplankton, nanoplankton, microplankton). All pixels that Alvain et al. (2008) categorize as either picoplankton (left set of bars) or microplankton (right set of bars) were used to calculate the respective mean and standard deviation (shown as error bar) of our PSD-based percent picoplankton (green) and percent microplankton contribution (yellow). Thus each bar represents the mean of the PSD-derived PFT's at all pixels that are categorically classified either as picoplankton or microplankton by the method of Alvain et al. (2008).

\subsection{Decadal-scale regional and global trends}

The SeaWiFS time series used here spans 124 months allowing assessment of decadal-scale monthly anomaly trends (See Sect. 2.5). All trends were based on the 2000-2007 period only (96 months) in order to avoid the strong ENSO years which dominate the trend for many variables (See
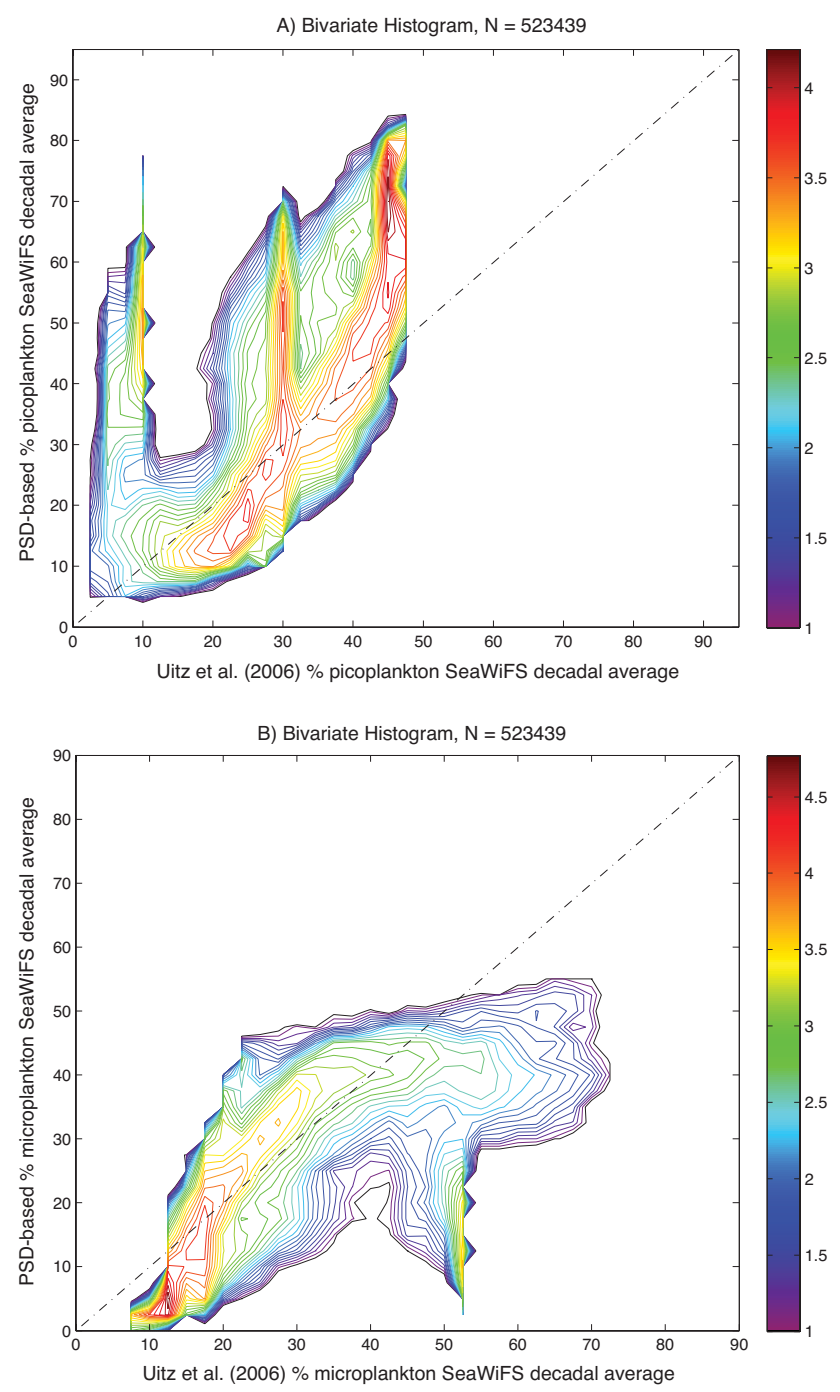

Fig. 12. Bivariate histograms comparing global SeaWiFS decadal averages of the PSD-based and the Uitz et al. (2006) PFT's. Pixel counts are on a logarithmic scale and are constructed only for pixels deeper than $200 \mathrm{~m}$. The one-to-one line is indicated as well. (A) Comparison for picoplankton-sized particles and (B) comparison for microplankton-sized particles.

Sect. 4.4. below, also Behrenfeld et al., 2006). Table 1 lists the significant trends in bold and italics (see the caption for the acronyms used below). Global SST trends exhibited a statistically significant warming (p-value of regression $<0.05$ ); however, when analyzed by region, warming was significant only in the $\mathrm{NH}$ cold waters and in the N.A. subtropical gyre (STG). In contrast to that, global chl exhibited a significant trend of decrease that was dominated by the warm waters, i.e. the subtropical gyres (except the SA STG). This observation is consistent with recent observations by Behrenfeld et al. (2006) and Polovina et al. (2008), who report a decrease in chl and primary productivity in the gyres or warm, stratified oceanic regions in the recent decade (after 
the strong increase during the La Niña in 1999). Gregg et al. (2005) report increasing chl in the coastal ocean and decreasing chl in the subtropical gyres in the 1998-2003 period. However, Gregg et al. (2003) analyzed the 1980's to 2002 period (using CZCS, SeaWiFS and in-situ data) and found ocean productivity decreases at the high latitudes instead, and increases at low latitudes, attributing the changes to changes in chl. Importantly, the analysis of Martinez et al. (2009) demonstrates that using different time periods for such trend analysis can lead to opposing results in many regions; they attribute the observations mostly to physical forcing related to PDO and AMO oscillations. The important unresolved issue is whether such a chl decrease is due to biomass decrease or to physiological adaptation or a combination of both (Behrenfeld et al., 2008). The PSD-based approach to calculating particle abundance and the PFT's has the potential to help resolve this issue by indicating whether particle abundance or the ecosystem structure have changed, independent of chl.

With the notable exception of the South Atlantic gyre, number concentrations of particles were trending down almost everywhere else, most significantly so for picoplankton-sized particles (which dominate the number concentration); this trend was significant globally, in the cold waters of both hemispheres and in some gyres, but not in all warm waters together. The nano- and microplankton-particle abundances did not exhibit a significant trend in most places, except for the NP STG where they were trending down and the SA STG, where interestingly they were trending up. The PSD slope trends were mostly insignificant, although a global decrease of $-0.02 /$ decade was significant (Table 1 trends are reported per year and multiplied by 100 for clarity), with the SA STG exhibiting the only other significant trend. The trends in the PFT's were rarely significant, with the exception of the SA STG again, where picoplanktonsized particles exhibited a marked decrease, compensated by increases in larger particles. The same was true globally, likely driven mostly by the strong trends in the SA STG. Most other places exhibited trends in the same direction, but rarely significant.

An increased oligotrophy (including a biomass decrease and a community shift to smaller phytoplankton) would be expected to exhibit not just lower chl, but also higher PSD slopes, lower particle abundances and increased percentage by volume of the picoplankton PFT, similarly to the seasonal decadal averages (Fig. 8; Sect. 3.3). This was generally not observed. While number concentrations indeed decreased most everywhere, so did the PSD slope and the picoplankton PFT percentage. The SA STG was an exception in many ways, consistently showing increased eutrophy, with no significant trend in chl or SST. Elsewhere there generally seemed to be a trend toward larger and/or fewer particles, even if chl was decreasing. It is hard to make any conclusive statements about physiological adaptations vs. biomass decrease from the trends in Table 1 (Behrenfeld et al., 2008).
Martinez et al. (2009) interpret their observed decadal-scale trends (1979-2002) as primarily due to biomass changes. Further work needs to be devoted to more careful validation and study of the parallel trends in the PSD products and their uncertainties in order to address this important issue. In summary, the PSD-based PFT and number concentration decadal-scale regional and global anomaly trends were generally inconclusive, and it should be kept in mind that the present analysis was performed on a relatively short timeseries ( 8 years), which emphasizes the need for further analysis and importantly, sustained high-quality ocean color observations in the future, especially in the context of global climate change (Henson et al., 2010).

\subsection{Global and regional effects of El-Niño/Southern Oscillation}

The El-Niño/Southern Oscillation (ENSO) phenomenon has a major effect on global ocean productivity, causing a pronounced decrease in chl in warm ocean waters during its warm phase (Behrenfeld et al., 2006). The SeaWiFS launch in August of 1997 was fortuitous in that it captured the strong El-Niño of the fall of 1998 and the subsequent strong LaNiña in 1999. We explored the global and regional effects of ENSO on SST, chl, the PSD-derived PFT's and other relevant variables. The multivariate ENSO index, MEI (Wolter and Timlin, 1998), was used as a monthly index of the status of ENSO, and the linear correlation coefficients of MEI with area-weighted regional or global anomalies are reported in Table 2 (see also Sects. 2.4 and 2.5). The entire data set (Sep 1997-Dec 2007, 124 months) was used for this analysis. The global correlations of MEI with the anomalies of all variables were significant, driven largely by correlations in the warm oceans, whereas correlations were weak or not significant in the cold oceans. As expected, during the warm phase of ENSO, SST's were rising globally; however interestingly the Pacific subtropical gyres exhibited cooling. Correspondingly, chl decreased globally, but no significant correlation was observed in the South Hemisphere cold waters or in the Pacific subtropical gyres.

Warm waters exhibited a significant increase in PSD slope, indicating increasing oligotrophy and a shift to smaller particles. Consistent with decreases in the global oceans surface chl, abundance correlations indicated there were generally fewer particles during a warm ENSO phase, and PFT's correlations indicated increases in percent contribution of picoplankton, and (with fewer significant correlations) decreases in percent contribution of microplankton. The South Pacific Subtropical Gyre and the cold waters of the oceans exhibited weak/insignificant correlations with MEI. In summary, anomaly correlations with the MEI index of ENSO were consistent with a global shift to less productive ecosystems (lower chl, smaller particle abundance and greater dominance of picoplankton-sized particles), driven largely by the warm oceans, consistent with Behrenfeld et al. (2006). 
Table 1. Statistics of decadal-scale trend analysis of monthly anomalies of the PSD algorithm base and derived products, as well as SST and OC4v4 chl. Type I regression slope is shown in the respective units indicated in the second column. For clarity, slope values were multiplied by 100. Regressions exclude the strong ENSO years of 1997, 1998 and 1999, i.e. they are based on the 8 years from 2000 to 2007 . Significant trends are indicated in bold and italics. Significant here means that the 95\% confidence interval of the slope of the regression of the monthly anomalies on time in years does not cross the zero line (alternatively, that the p-value of the regression is less than 0.05, Walpole et al., 1998). Only pixels deeper than $200 \mathrm{~m}$ were considered. See Sects. 2.4 and 2.5 for details. Acronyms used are: NH - North Hemisphere; SH - South Hemisphere; NA - North Atlantic; SA - South Atlantic; NP - North Pacific; SP - South Pacific; IO - Indian Ocean; STG - subtropical gyre.

\begin{tabular}{|c|c|c|c|c|c|c|c|c|c|c|}
\hline $\begin{array}{l}\text { Variable } \\
\text { /Region }\end{array}$ & $\begin{array}{l}\text { Slope Units } \\
\text { (regression based } \\
\text { on 2000-2007 } \\
\text { period) }\end{array}$ & Global & NH Cold & Warm & SH Cold & NA STG & NP STG & SA STG & SP STG & IO STG \\
\hline SST & ${ }^{\circ} \mathrm{Cy}^{-1}(\mathrm{x} 100)$ & 2.04 & 5.89 & 0.77 & 0.52 & 3.10 & 0.83 & 1.17 & 0.81 & 1.41 \\
\hline chl & $\log 10\left(\mathrm{mg} \mathrm{m}^{-3}\right) \mathrm{y}^{-1}(\mathrm{x} 100)$ & -0.27 & -0.09 & -0.27 & -0.03 & -0.41 & -0.46 & -0.12 & -0.47 & -0.48 \\
\hline$\xi$ & $\mathrm{y}^{-1}(\mathrm{x} 100)$ & -0.20 & -0.10 & -0.10 & -0.19 & 0.28 & 0.39 & -0.70 & -0.16 & 0.14 \\
\hline N_pico & $\log 10\left(m^{-3}\right) y^{-1}(x 100)$ & -0.19 & -0.29 & -0.18 & -0.50 & -0.45 & -0.49 & 0.28 & 0.02 & -0.46 \\
\hline N_nano & $\log 10\left(m^{-3}\right) y^{-1}(x 100)$ & -0.07 & -0.22 & -0.11 & -0.38 & -0.62 & -0.73 & 0.71 & 0.12 & -0.55 \\
\hline N_micro & $\log 10\left(m^{-3}\right) y^{-1}(x 100)$ & 0.12 & -0.13 & -0.02 & -0.20 & -0.90 & -1.11 & 1.39 & 0.27 & -0.68 \\
\hline$\%$ pico & $\% y^{-1}(x 100)$ & -9.56 & -0.46 & -6.77 & -8.48 & 7.57 & 12.00 & -30.58 & -9.56 & 2.28 \\
\hline$\%$ nano & $\% y^{-1}(x 100)$ & -1.64 & -6.35 & -0.03 & -7.53 & -9.48 & -9.49 & 14.92 & 3.83 & -3.25 \\
\hline$\%$ micro & $\% y^{-1}(x 100)$ & 11.20 & 6.80 & 6.80 & 16.01 & 1.92 & -2.51 & 15.66 & 5.73 & 0.97 \\
\hline
\end{tabular}

Table 2. Table of linear correlation coefficients of the monthly anomalies of SST, chl, and PSD variables with the multivariate ENSO index (MEI). Period of analysis: Sep 1997-Dec 2007 (124 months). Significant correlations at the 95\% confidence level are indicated in bold and italics. The MEI used is in units of 1/1000's of standard deviations (Wolter and Timlin, 1998, see also web link in Sect. 2.5). A positive MEI corresponds to the warm phase of El-Niño, i.e. a positive correlation coefficient means that the variable was increasing in value when there were El-Niño events and/or that it was decreasing in value when there were La-Niña events. All months that are involved in trend computations are included here, i.e. winter months are excluded from the polar regions, just like for the trends analysis (Sects. 2.4 and 2.5 ).

\begin{tabular}{|c|c|c|c|c|c|c|c|c|c|c|}
\hline Variable/Region & Variable units & Global & NH Cold & Warm & SH Cold & NA & NP & SA & SP & $\mathrm{IO}$ \\
\hline SST & ${ }^{\circ} \mathrm{C}$ & 0.61 & 0.35 & 0.63 & 0.22 & 0.34 & -0.27 & 0.37 & -0.50 & 0.50 \\
\hline chl & $\log 10\left(\mathrm{mg} \mathrm{m}^{-3}\right)$ & -0.61 & -0.23 & -0.65 & -0.14 & -0.29 & -0.17 & -0.27 & 0.02 & -0.32 \\
\hline$\xi$ & - & 0.33 & 0.07 & 0.38 & 0.05 & 0.23 & 0.34 & 0.21 & -0.03 & 0.24 \\
\hline N_pico & $\log 10\left(\mathrm{~m}^{-3}\right)$ & -0.40 & -0.19 & -0.42 & -0.12 & -0.25 & -0.35 & -0.27 & 0.00 & -0.30 \\
\hline N_nano & $\log 10\left(\mathrm{~m}^{-3}\right)$ & -0.38 & -0.16 & -0.41 & -0.09 & -0.24 & -0.35 & -0.24 & 0.01 & -0.28 \\
\hline N_micro & $\log 10\left(m^{-3}\right)$ & -0.36 & -0.12 & -0.40 & -0.08 & -0.24 & -0.35 & -0.23 & 0.02 & -0.26 \\
\hline$\%$ pico & $\%$ & 0.34 & 0.12 & 0.39 & 0.03 & 0.23 & 0.35 & 0.16 & 0.02 & 0.20 \\
\hline$\%$ nano & $\%$ & -0.39 & -0.25 & -0.41 & -0.12 & -0.23 & -0.31 & -0.24 & 0.01 & -0.22 \\
\hline$\%$ micro & $\%$ & -0.25 & -0.05 & -0.35 & 0.04 & -0.20 & -0.40 & -0.03 & -0.07 & -0.13 \\
\hline
\end{tabular}

\section{Summary and conclusions}

The ability to assess the structure and function of oceanic ecosystems from global satellite imagery is of paramount importance for understanding ocean biota's role in the carbon cycle on various time scales, which is relevant to assessing the ocean's role in climate processes. Chlorophyll concentration, a standard ocean color remote sensing product, has been used in existing studies in conjunction with in-situ data to construct models of phytoplankton functional type abundance and spatio-temporal distribution. Here, a novel algorithm was proposed that uses retrievals of the particle size distribution (PSD) (based on backscattering spectra) to esti- mate three PFT classes based on size. PFT's were estimated as the picoplankton, nanoplankton and microplankton-sized particle contribution to total volume concentration in the 0.5 to $50 \mu \mathrm{m}$ particle diameter range. As such, they are a function of the retrieved PSD power-law slope and the chosen limits of integration. Validation of the method with in-situ HPLC diagnostic pigment data yields considerable discrepancies; multiple reasons for those are detailed in Sect. 4.2. Global spatio-temporal patterns of the retrieved PFT's were consistent with current ecosystem understanding, indicating numerical dominance of picoplankton everywhere, whereas oligotrophic areas were picoplankton-dominated by volume, nanoplankton was ubiquitous in transition areas, and 
microplankton contributed significantly to total volume only in highly productive areas. Decadal trend analysis of the PFT's was inconsistent, indicating that recent reports of increased oligotrophy based on chlorophyll may not be enough to assess ecosystem change properly. Correlations with the MEI index were consistent with increased oligotrophy during a warm ENSO phase. Improved in-situ understanding of oceanic particle assemblages and the associated backscattering spectra as well as dominant phytoplankton functional types and their biogeochemical roles are all areas that need to be emphasized in future work.

Acknowledgements. The authors would like to acknowledge NASA Ocean Biology and Biogeochemistry Program for their support of this work (grants NNG06GE77G, NNX08AG82G, NNX08AF99A, NNX08AP36A \& NNX09AL09G). We acknowledge the NASA GSFC Ocean Biology Processing Group and GeoEye Inc. (formerly ORBIMAGE) for the SeaWiFS data products. NASA, SeaBASS, and the original data contributors are acknowledged for providing in-situ HPLC data. The acquisition of BIOSOPE data was funded through Centre National de Recherche Scientifique (CNRS) and Institut National des Sciences de 1'Univers (INSU) grants, France. We acknowledge Severine Alvain, Julia Uitz and Hervé Claustre for providing us with HPLC \& PFT data, Sergio Signorini for providing us with bathymetry data, Phillip Schneider for help with SST data and Peter Bodin and Bolu Ajiboye for their graphing scripts.

Edited by: A. Bricaud

\section{References}

Alvain, S., Moulin, C., Dandonneau, Y., and Breon, F. M.: Remote sensing of phytoplankton groups in case 1 waters from global SeaWiFS imagery, Deep Sea Res. Pt. I, 52, 11, 19892004, doi:10.1016/j.dsr.2005.06.015, 2005.

Alvain, S., Moulin, C., Dandonneau, Y., and Loisel, H.: Seasonal distribution and succession of dominant phytoplankton groups in the global ocean: A satellite view, Global Biogeochem. Cy., 22, GB3001, doi:10.1029/2007GB003154, 2008.

Bailey, S. W. and Werdell, P. J.: A multi-sensor approach for the on-orbit validation of ocean color satellite data products, Remote Sens. Environ., 102(1-2), 12-23, doi:10.1016/j.rse.2006.01.015, 2006.

Behrenfeld, M. and Falkowski, P.: A consumer's guide to phytoplankton primary productivity models, Limnol. Oceanogr., 42(7), 1479-1491, 1997.

Behrenfeld, M. J., Boss, E., Siegel, D. A., and Shea, D. M.: Carbon-based ocean productivity and phytoplankton physiology from space, Global Biogeochem. Cy., 19, GB1006, doi:10.1029/2004GB002299, 2005.

Behrenfeld, M. J., OMalley, R. T., Siegel, D. A., McClain, C. R., Sarmiento, J. L., Feldman, G. C., Milligan, A. J., Falkowski, P. G., Letelier, R. M., and Boss, E. S.: Climate-driven trends in contemporary ocean productivity, Nature, 444, 752-755, 2006.

Behrenfeld, M. J, Halsey, K. H, and Milligan, A. J.: Evolved physiological responses of phytoplankton to their integrated growth environment,Phil. Trans. R. Soc. B., 363, 2687-2703, doi:10.1098/rstb.2008.0019, 2008.

Bonnet, S., Guieu, C., Bruyant, F., Prášil, O., Van Wambeke, F., Raimbault, P., Moutin, T., Grob, C., Gorbunov, M. Y., Zehr, J. P., Masquelier, S. M., Garczarek, L., and Claustre, H.: Nutrient limitation of primary productivity in the Southeast Pacific (BIOSOPE cruise), Biogeosciences, 5, 215-225, doi:10.5194/bg-5-215-2008, 2008.

Boyd, P. W. and Harrison, P. J. Phytoplankton dynamics in the NE subarctic Pacific, Deep-Sea Res. Pt. II, 46, 2405-2432, 1999.

Buesseler, K. O., Lamborg, C. H., Boyd, P. W., Lam, P. J., Trull, T. W., Bidigare, R. R., Bishop, J. K. B., Casciotti, K. L., Dehairs, F., Elskens, M., Honda, M., Karl, D. M., Siegel, D. A., Silver, M. W., Steinberg, D. K., Valdes, J. B., Mooy, B. V., and Wilson, S.: Revisiting Carbon Flux through the Ocean's Twilight Zone, Science, 316, 567-570, 2007.

Cho, B. C and Azam, F.: Major role of bacteria in biogeochemical fluxes in the ocean's interior, Nature, 332, 441-443, 1988.

Claustre, H., Sciandra, A., and Vaulot, D.: Introduction to the special section bio-optical and biogeochemical conditions in the South East Pacific in late 2004: the BIOSOPE program, Biogeosciences, 5, 679-691, doi:10.5194/bg-5-679-2008, 2008.

Clavano, W. R., Boss, E., and Karp-Boss, L.: Inherent optical properties of non-spherical marine-like particles - from theory to observation, Oceanogr. Mar. Biol., 45, 1-38, 2007.

Del Vecchio, R., and Subramaniam, A.: Influence of the Amazon River on the surface optical properties of the western tropical North Atlantic Ocean, J. Geophys. Res., 109, 1-13, 2004.

Dall'Olmo, G., Westberry, T. K., Behrenfeld, M. J., Boss, E., and Slade, W. H.: Significant contribution of large particles to optical backscattering in the open ocean, Biogeosciences, 6, 947-967, doi:10.5194/bg-6-947-2009, 2009.

Eppley, R. W., Holmes, R. W., and Strickland II., J. D.: Sinking rates of marine phytoplankton measured with a fluorometer, J. exp. mar. Biol. Ecol., 1, 191-208, 1967.

Eppley, R. W. and Peterson, B. J.: Particulate organic matter flux and planktonic new production in the deep ocean, Nature, 282, 677-680, 1979.

Falkowski, P. G., Barber, R. T., Smetacek, V.: Biogeochemical controls and feedbacks on ocean primary production, Science, 281, 200-206, 1998.

Falkowski P. G., Laws, E. A., Barber, R. T., et al.: Phytoplankton and their role in primary, new, and export production, in: Ocean Biogeochemistry: The Role of the Ocean Carbon Cycle in Global Change, edited by: Fasham, M. J. R., 99-121, Springer, Berlin, 2003.

Field, C. B., Behrenfeld, M. J., Randerson, J. T., and Falkowski, P.: Primary production of the biosphere: Integrating terrestrial and oceanic components, Science, 281, 237-240, 1998.

Garver, S. A. and Siegel, D. A.: Inherent optical property inversion of ocean color spectra and its biogeochemical interpretation, 1, Time series from the Sargasso Sea, J. Geophys. Res., 102, 18607-18625, 1997.

Gregg, W. W., Conkright, M. E., Ginoux, P., O’Reilly, J. E., and Casey, N. W.: Ocean primary production and climate: Global decadal changes, Geophys. Res. Lett., 30(15), 1809, doi:10.1029/2003GL016889, 2003.

Gregg, W. W., Casey, N. W., and McClain, C. R.: Recent trends in global ocean chlorophyll, Geophys. Res. Lett., 32, L03606, 
doi:10.1029/2004GL021808, 2005.

Harrison, P. J.: Station Papa Time Series: Insights into Ecosystem Dynamics, J. Oceanogr. 58, 259-264, 2002.

Henson, S. A., Sarmiento, J. L., Dunne, J. P., Bopp, L., Lima, I., Doney, S. C., John, J., and Beaulieu, C.: Detection of anthropogenic climate change in satellite records of ocean chlorophyll and productivity, Biogeosciences, 7, 621-640, doi:10.5194/bg7-621-2010, 2010.

Hood, R. R., Laws, E. A., Armstrong, R. A., Bates, N. R., Brown, C. W., Carlson, C. A., Chai, F., Doney, S. C., Falkowski, P. G., Feely, R. A., Friedrichs, M. A. M., Landry, M. R., Moore, J. K., Nelson, D. M., Richardson, T. L., Salihoglu, B., Schartau, M., Toole, D. A., and Wiggert, J. D.: Pelagic functional group modeling: Progress, challenges and prospects, Deep-Sea Res. Pt. II, 53, 459-512, 2006.

IOCCG: Remote Sensing of Ocean Colour in Coastal, and Other Optically-Complex, Waters, edited by: Sathyendranath, S., Reports of the International Ocean-Colour Coordinating Group, No. 3, IOCCG, Dartmouth, Canada, 2000.

IOCCG: Ocean-Colour Data Merging. edited by: Gregg, W., Reports of the International Ocean-Colour Coordinating Group, No. 6, IOCCG, Dartmouth, Canada, 2007.

IPCC: Climate Change 2007: The Physical Science Basis, in: Contribution of Working Group I to the Fourth Assessment Report of the Intergovernmental Panel on Climate Change, edited by: Solomon, S., Qin, D., Manning, M., Chen, Z., Marquis, M., Averyt, K. B., Tignor, M. and Miller, H. L., Cambridge University Press, Cambridge, UK and New York, NY, USA, 996 pp., 2007.

Karl, D. M., Christian, J. R., Dore, J. E., Hebel, D. V., Letelier, R. M., Tupas, L. M., and Winn, C. D.: Seasonal and interannual variability in primary production and particle flux at Station ALOHA, Deep-Sea Res. Pt. II, 43, 539-568, 1996.

Keeling, R. F., Körtzinger A.,and Gruber, N.: Ocean deoxygenation in a warming world, Ann. Rev. Mar. Sci., 2, 199-229, 2010.

Kostadinov, T. S., Siegel, D. A., Maritorena, S., and Guillocheau, N.: Ocean color observations and modeling for an optically complex site: Santa Barbara Channel, California, USA, J. Geophys. Res., 112, C07011, doi:10.1029/2006JC003526, 2007.

Kostadinov, T. S., Siegel, D. A., and Maritorena, S.: Retrieval of the particle size distribution from satellite ocean color observations, J. Geophys. Res., 114, C09015, doi:10.1029/2009JC005303, 2009.

Le Quéré, C., Harrison, S. P., Colin Prentice, I., Buitenhuis, E. T., Aumont, O., Bopp, L., Claustre, H., Cotrim Da Cunha, L., Geider, R., Giraud, X., Klaas, C., Kohfeld, K. E., Legendre, L., Manizza, M., Platt, T., Rivkin, R. B., Sathyendranath, S., Uitz, J., Watson, A. J., and Wolf-Gladrow, D.: Ecosystem dynamics based on plankton functional types for global ocean biogeochemistry models, Glob. Change Biol., 11, 2016-2040, doi:10.1111/j.1365-2486.2005.1004.x, 2005.

Lee, Z. P., Carder, K. L., and Arnone, R.: Deriving inherent optical properties from water color: A multi-band quasi-analytical algorithm for optically deep waters, Appl. Optics, 41, 5755-5772, 2002.

Lochte, K., Ducklow, H. W., Fasham, M. J. R., and Stienen, C.: Plankton Succession and Carbon Cycling at $47^{\circ} \mathrm{N} 20^{\circ} \mathrm{W}$ during the JGOFS North-Atlantic Bloom Experiment, Deep-Sea Res. Pt. II, 40, 91-114, 1993.

Loisel, H. and Stramski, D.: Estimation of the inherent optical prop- erties of natural waters from irradiance attenuation coefficient and reflectance in the presence of Raman scattering, Appl. Optics, 39, 3001-3011, 2000.

Loisel, H., Nicolas, J.-M., Sciandra, A., Stramski, D., and Poteau, A.: Spectral dependency of optical backscattering by marine particles from satellite remote sensing of the global ocean, J. Geophys. Res., 111, C09024, doi:10.1029/2005JC003367, 2006.

Longhurst, A.: Ecological Geography of the Sea, 2nd Ed., Academic Press, San Diego, Calif, 2007.

Maritorena, S., Siegel, D., and Peterson, A.: Optimization of a semi-analytical ocean color model for global-scale applications, Appl. Optics, 41(15), 2705-2714, 2002.

Maritorena S., Hembise Fanton d'Andon, O., Mangin, A., and Siegel, D. A.: Merged Satellite Ocean Color Data Products Using a Bio-Optical Model: Characteristics, Benefits and Issues, Remote Sens. Environ., 114(8), 1791-1804, 2010.

Martinez, E., Antoine, D., D’Ortenzio, F., and Gentili, B.: ClimateDriven Basin-Scale Decadal Oscillations of Oceanic Phytoplankton, Science, 326, 1253-1256, doi:10.1126/science.1177012, 2009.

McCave, I. N.: Vertical flux of particles in the ocean, Deep Sea Res., 22(7), 491-502, 1975.

McClain, C. R., Signorini, S. R., and Christian, J. R.: Subtropical gyre variability observed by ocean-color satellites, Deep Sea Res. Pt II, 51, 281-301, 2004.

McClain, C. R.: A decade of satellite ocean color observations, Annual Review of Marince Science, 1, 19-42, 2009.

Morel, A. and Mueller, J.: Normalized Water-Leaving Radiance and Remote Sensing Reflectance: Bidirectional Reflectance and Other Factors, Ch. 4., in: Ocean Optics Protocols For Satellite Ocean Color Sensor Validation, edited by: Mueller, J. L., Fargion, G. S. and McClain, C. R., Revision 4, Volume III, NASA/TM-2003-21621/Rev-Vol III, 2003.

Nair, A., Sathyendranath, S., Platt, T., Morales, J., Stuart, V., Forget, M.-H., Devred, E., and Bouman, H.: Remote sensing of phytoplankton functional types, Remote Sens. Environ., 112, 33663375, 2008.

O’Reilly, J. E., Maritorena, S., Mitchell, B. G., Siegel, D. A., Carder, K. L., Garver, S. A., Kahru, M., and McClain, C. R.: Ocean color chlorophyll algorithms for SeaWiFS, J. Geophys. Res., 103, 24937-24953, 1998.

O'Reilly, J. E., Siegel, D. A., Mueller, J., and 22 coauthors: SeaWiFS Postlaunch Calibration and Validation Analyses, Part 3., NASA Tech. Memo., 2000-206892, Vol. 11, edited by: Hooker, S. B. and Firestone, E. R., NASA Goddard Space Flight Center, 49 pp., 2000.

Polovina, J. J., Howell, E. A., and Abecassis, M.: Ocean's least productive waters are expanding, Geophys. Res. Lett., 35, L03618, doi:10.1029/2007GL031745, 2008.

Sieburth, J. M., Smetacek, V., and Lenz, J.: Pelagic ecosystem structure: heterotrophic compartments of the plankton and their relationship to plankton size fractions, Limnol. Oceanogr., 23, 1256-1263, 1978.

Siegel, D. A., Nelson, N. B., O’Brien, M. C., Westberry, T. K., et al.: The Bermuda BioOptics Project: Bio-optical modeling of primary production from space-sensible variables, Deep Sea Res. Pt. II, 48, 1865-1896, 2001.

Siegel, D. A., Doney, S. C., and Yoder, J. A.: The North Atlantic spring phytoplankton bloom and Sverdrup's critical depth hy- 
pothesis, (Wash.), Science, 296, 730-733, 2002.

Siegel, D. A., Maritorena, S., Nelson, N. B., and Behrenfeld, M. J.: Independence and interdependencies among global ocean color properties: Reassessing the bio-optical assumption, J. Geophys. Res., 110, C07011, doi:10.1029/2004JC002527, 2005.

Signorini, S., McClain, C. R., and Dandonneau, Y.: Mixing and phytoplankton bloom in the wake of the Marquesas Islands, Geophys. Res. Lett., 26, 3121-3124, 1999.

Smith, R. C. and Baker, K. S.: Optical classification of natural waters, Limnol. Oceanogr., 23, 260-267, 1978.

Stemmann, L., Jackson, G. A., and Ianson, D.: A vertical model of particle size distributions and fluxes in the midwater column that includes biological and physical processes - Part I: model formulation, Deep Sea Res. Pt. I, 51(7), 865-884, doi:10.1016/j.dsr.2004.03.001, 2004.

Stramski, D., Boss, E., Bogucki, D., and Voss, K. J.: The role of seawater constituents in light backscattering in the ocean, Prog. Oceanogr., 61, 27-55, 2004.

Stramski, D., Reynolds, R. A., Babin, M., Kaczmarek, S., Lewis, M. R., Rttgers, R., Sciandra, A., Stramska, M., Twardowski, M. S., Franz, B. A., and Claustre, H.: Relationships between the surface concentration of particulate organic carbon and optical properties in the eastern South Pacific and eastern Atlantic Oceans, Biogeosciences, 5, 171-201, doi:10.5194/bg-5-171-2008, 2008.

Subramaniam, A., Yager, P. L., Carpenter, E. J., Mahaffey, C., Björkman, K., Cooley, S., Kustka, A. B., Montoya, J. P., SañudoWilhelmy, S. A., Shipe, R., and Capone, D. G.: Amazon River enhances diazotrophy and carbon sequestration in the tropical North Atlantic Ocean, P. Natl. A. Sci., 105, 10460-10465, 2008.
Sverdrup, H. U.: On conditions for the vernal blooming of phytoplankton, J. Cons. Int. Explor. Mer., 18, 287-295, 1953.

Ternon, J. F., Oudot, C., Dessier, A., and Diverres, D.: A seasonal tropical sink for atmospheric $\mathrm{CO}_{2}$ in the Atlantic ocean: the role of the Amazon River discharge, Mar. Chem., 68, 183-201, 2000.

Uitz, J., Claustre, H., Morel, A., and Hooker, S. B.: Vertical distribution of phytoplankton communities in open ocean: An assessment based on surface chlorophyll, J. Geophys. Res., 111, C08005, doi:10.1029/2005JC003207, 2006.

Uitz, J., Claustre, H., Gentili, B., and Stramski, D.: Phytoplankton class-specific primary production in the world's oceans: Seasonal and interannual variability from satellite observations, Global Biogeochem. Cy., 24, GB3016, doi:10.1029/2009GB003680, 2010.

Vidussi, F., Claustre, H., Manca, B. B., Luchetta, A., and Marty, J. C.: Phytoplankton pigment distribution in relation to upper thermocline circulation in the eastern Mediterranean Sea during winter, J. Geophys. Res., 106(C9), 19939-19956, 2001.

Walpole, R. E., Myers, R. H., and Myers, S. L.: Probability and Statistics for Engineers and Scientists, 6th ed., 739 pp., PrenticeHall, Upper Saddle River, N.J., 1998.

Werdell, P. J., Bailey, S. W., Fargion, G. S., Pietras, C., Knobelspiesse, K. D., Feldman, G. C., and McClain, C. R.: Unique data repository facilitates ocean color satellite validation, EOS Trans. AGU, 84, 38, 377, 2003.

Whitney, F. A. and Freeland, H.: Variability in upper-ocean water properties in the NE Pacific Ocean, Deep Sea Res. Pt. II, 46, 2351-2370, 1999.

Wolter, K. and Timlin, M. S.: Measuring the strength of ENSO events - how does 1997/98 rank? Weather, 53, 315-324, 1998. 